\title{
Status of mannose-binding lectin (MBL) and complement system in COVID-19 patients and therapeutic applications of antiviral plant MBLs
}

\author{
Anita Gupta ${ }^{1}$. G. S. Gupta ${ }^{2}$ (I) \\ Received: 9 September 2020 / Accepted: 11 February 2021 / Published online: 21 March 2021 \\ (c) The Author(s), under exclusive licence to Springer Science+Business Media, LLC, part of Springer Nature 2021
}

\begin{abstract}
Coronavirus disease 2019 (COVID-19) is an infectious disease caused by a virus called "Severe Acute Respiratory Syndrome Coronavirus 2 (SARS-CoV-2)." In the majority of patients, infection with COVID-19 may be asymptomatic or may cause only mild symptoms. However, in some patients, there can also be immunological problems, such as macrophage activation syndrome (CSS) that results in cytokine storm syndrome (CSS) and acute respiratory distress syndrome (ARDS). Comprehension of host-microbe communications is the critical aspect in the advancement of new therapeutics against infectious illnesses. Endogenous animal lectins, a class of proteins, may perceive non-self glycans found on microorganisms. Serum mannose-binding lectin (sMBL), as a part of the innate immune framework, recognizes a wide range of microbial microorganisms and activates complement cascade via an antibody-independent pathway. Although the molecular basis for the intensity of SARS-CoV-2 infection is not generally understood, scientific literature indicates that COVID-19 is correlated with unregulated activation of the complement in terms of disease severity. Disseminated intravascular coagulation (DIC), inflammation, and immune paralysis contribute to unregulated complement activation. Pre-existing genetic defects in MBL and their association with complement play a major role in immune response dysregulation caused by SARS-CoV-2. In order to generate anti-complement-based therapies in Covid-19, an understanding of sMBL in immune response to SARS-CoV-2 and complement is therefore essential. This review highlights the role of endogenous sMBL and complement activation during SARS-CoV-2 infection and their therapeutic management by various agents, mainly plant lectins, since antiviral mannose-binding plant lectins (pMBLs) offer potential applications in the prevention and control of viral infections.
\end{abstract}

Keywords Lectins $\cdot$ Mannose-binding lectins $\cdot$ Complement $\cdot$ NK cells $\cdot$ Plant lectins $\cdot$ CoV-2 $\cdot$ COVID-19

\section{Introduction}

Coronavirus disease 2019 (COVID-19) is an infectious disease caused by a new coronavirus called Acute Respiratory Distress Syndrome Coronavirus 2 (ARDS-CoV-2). On January 30, 2020, as it had spread to 18 countries with four countries confirming human-to-human transmission, the World Health Organization (WHO) declared the Covid-19 outbreak as an international public concern. The disease

$\triangle$ G. S. Gupta

drgsgupta55@gmail.com

1 Chitkara School of Health Sciences, Chitkara University, Rajpura, Punjab, India

2 Department of Biophysics, Sector 25, Panjab University, Chandigarh 160014, India was announced by the WHO on March 11, 2020, as a pandemic. Over the last 20 years, there have been two more CoV epidemics: (i) SARS-CoV, which has triggered a largescale outbreak in China and two dozen other nations, and (ii) MERS-CoV, which started in Saudi Arabia. Through droplets or direct touch, COVID-19 is spread by humanto-human transmission. In patients with pneumonia caused by infection with SARS-CoV-2, fever is the most frequent symptom, accompanied by dry cough. There are common anomalies in CT scans of the patient's lungs [1]. From moderate common cold to life-threatening illness, COVID-19 may present symptoms of a wide range of diseases: acute respiratory distress syndrome (ARDS), multi-organ failure, and shock. Immune dysfunction, leading to what is called 'cytokine storm syndrome (CSS),' which results in the release of pro-inflammatory cytokines and ARDS in 15-20\% of severe Covid-19 patients, is the main step in transforming 
mild disease into severe illness. In order to minimize the subsequent effects, it is important to detect cytokine storms early in the course of the disease. After SARS-CoV and MERS-CoV in the twenty-first century, SARS-CoV-2 has been labeled as a new highly pathogenic coronavirus in the human population. In addition to the strict global outbreak control that has been adopted, the incidence of COVID-19 continues to increase, contributing to the pandemic disease that infected more than 100 million individuals until January, 27, 2021, and causing 2.16 millions deaths worldwide, thus representing an extremely serious threat to human life. Despite, current sufficient-scientific efforts, there are a number of gaps in the understanding of the immunological basis of CSS in severe COVID-19 patients. Therefore, this article reviews the present knowledge of the complement system of immune activation, the role of mannose-binding lectin (MBL) and manifestations of serum MBL (sMBL) levels during the early onset of COVID-19 and (ii) to review and recommend the mannose-specific antiviral plant lectins for the prevention and treatment of COVID-19 patients.

\section{SARS-CoV-2 virus}

The SARS-CoV-2, responsible for the etiology of COVID19 , appears to be very infectious since it has spread rapidly globally. The new virus, initially named 2019-nCoV, was later named the SARS-CoV-2 virus, because it is very similar to the one that triggered the outbreak of SARS (SARS$\mathrm{CoVs}$ ). CoVs are the primary pathogens of emerging outbreaks of respiratory diseases including ARDS and can be isolated from various species of animals. CoVs belong to a large family of single-stranded RNA viruses (+ ssRNA). These viruses can cross barriers to organisms and can cause diseases ranging from common cold to more serious diseases in humans.

The magnitude of SARS-CoV-2 infection depends on environmental conditions. Climatic conditions are important for respiratory disorders, although the controversial effects of the climatic conditions have been reported against COVID-19. SARS-CoV-2 infection can cause cardiac injury via multiple mechanism, including the cytokine storm. These responses lead to multi-organ failure. The clinical results of COVID-19 on patients with cardiovascular diseases and cardiopulmonary injuries have been reported [2]. COVID-19 accelerates the pathogenesis of the neurological disorders, although the pathogenic mechanisms between COVID-19 and neurological disorders are not very clear [3].

\section{Structure of coronavirus}

Li et al. [4] have depicted the phylogenetic tree of SARSlike coronaviruses and their full-genome sequences. The coronavirus virions are spherical in shape with diameters of approximately $125 \mathrm{~nm}$ [5] under cryoelectron microscopy. Prominent characteristics of coronaviruses are the club-shaped spikes on the surface of the virions. These spikes appear as a structure similar to a solar corona, from which the term "coronavirus" was derived. The nucleocapsids are helically symmetric and are filled with the virion's envelope. Coronaviruses proteins are marked by a letter S (protuberance), E (envelope), M (membrane), and $\mathrm{N}$ (membrane) (nucleocapsid) according to their position on the virus. Certain virions, in subgroup A, have characteristic hemagglutinin esterase activity. The SARS coronavirus $\mathrm{S}$ protein possesses a specific binding site for viral entry into the host cell.

Surface-located envelope spike (S) is a glycoprotein, which mediates the entry of $\mathrm{CoV}$ in human cells [6] (Fig. 1). In most cases, the $\mathrm{S}$ protein is divided by host proteases into subunits of $\mathrm{S} 1$ and $\mathrm{S} 2$, responsible for angiotensin-converting enzyme 2 (ACE2) as receptor recognition and membrane fusion, respectively. The ACE2 is recognized as a receptor-binding domain (RBD) by both the N-terminal domain (NTD) and the C-terminal domain (CTD) of CoV S1 [7]. The interaction site of the S protein for ACE2 has been examined by Wang et al. [7].

SARS-CoV-2 infects human cells by binding to ACE2 and the transmembrane serine protease 2 (TMPRSS2) for priming of the spike (S) protein of the virus. The activity of the endosomal/lysosomal cysteine proteases cathepsin$B$ and -L (CTSB and CTSL) can also be required for the entry of the virus, but their activity is likely to be dispensable [8].

\section{Glycosylated S protein interacts with multiple immune receptors}

During host cell invasion, spike (S1) glycoprotein binds to receptors on cell membranes, such as ACE2 $[9,10]$. Densely glycosylated with multiple asparagine-linked (N-glycans) and a few serine/threonine-linked (O glycans) $[11,12]$ in the $\mathrm{S} 1$ of SARS-CoV-2 presents ligands for a variety of innate immune receptors, including C-type lectin receptors (CLRs) that are known to bind specific glycans mostly in a C-type lectin-dependent manner [13]. C-type lectin receptors, such as "DC-SIGN (dendritic cell-specific intercellular adhesion molecule-3-grabbing non-integrin), L-SIGN (lymph nodespecific intercellular adhesion molecule-3-grabbing integrin), MMR (macrophage mannose receptor), macrophage galactose-type lectin (MGL), and Dectin-2, are highly expressed within the human immune cells, including monocytes, macrophages, and dendritic cells, functioning as the first-line of defense against invading viruses and pathogens" [13-16]. 


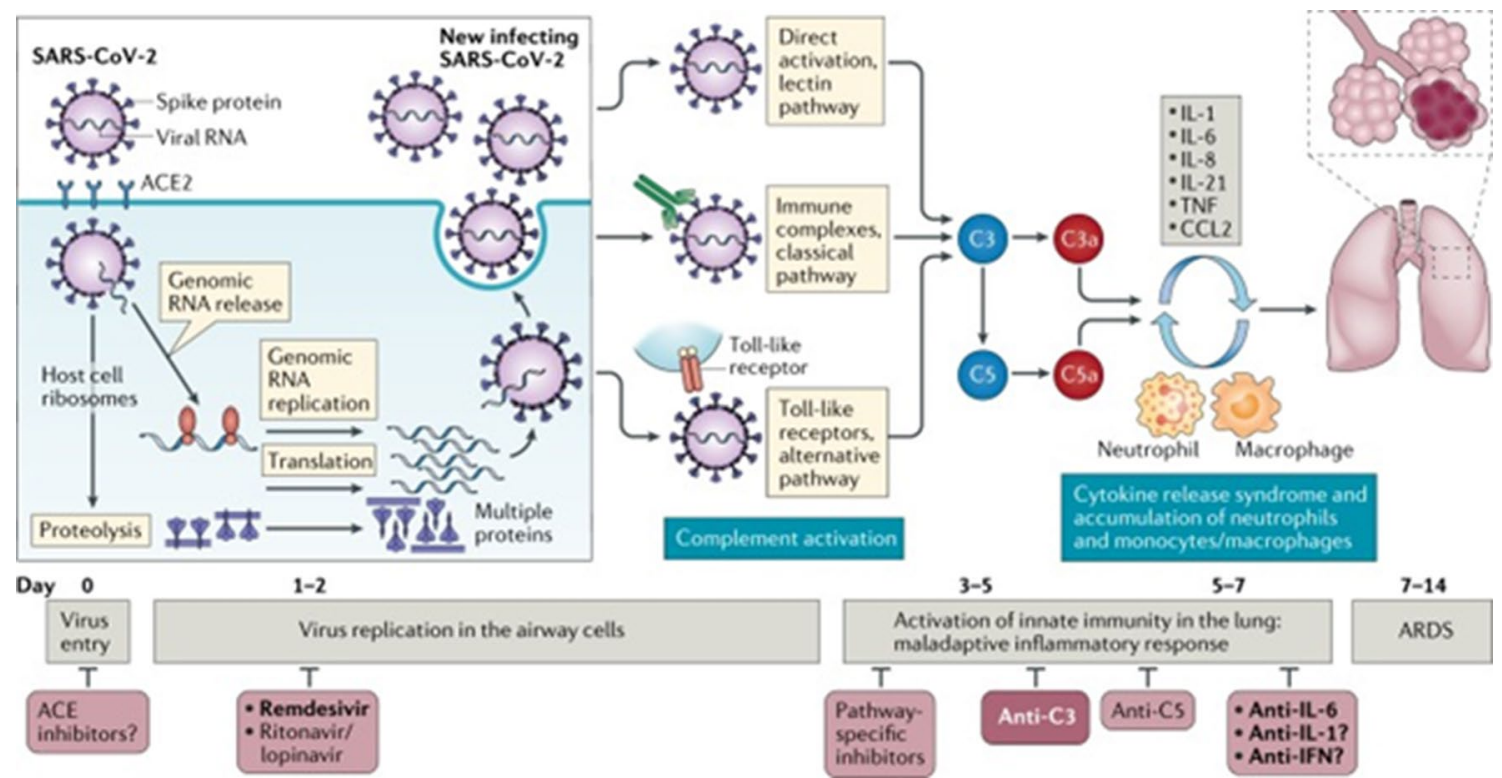

Fig. 1 Start of entry of SARS-CoV-2 (day 1) affecting innate immune response (days 3-5), maladaptive inflammatory response (days 5-7), and ARDS (days 7-14) in serious cases Courtesy: Risitano et al. [113]

\section{Lectin-carbohydrate interactions}

Protein-carbohydrate interactions underlie many biological events. In human infection by microbial pathogens, such interactions play a key role. Protein-carbohydrate interactions are chemically weak and depend on physiological conditions such as association with other proteins and $\mathrm{pH}$ conditions. The unique binding of extracellular matrix (ECM) or cell surface glycans to cell surface-associated lectins is mediated by protein-carbohydrate interactions and forms the major basis of biological processes such as embryogenesis, carcinogenesis and innate immunity.

In multivalent carbohydrates and glycoprotein receptors, the density and number of glycan epitopes are essential determinants of the binding and crosslinked activities of lectins and their roles as effectors [17, 18]. In matter of biochemical/physicochemical properties, molecular structure and carbohydrate-binding specificity of plant lectins are different from animal lectins [15]. Lectins show molecular sizes ranging from 60 to $400 \mathrm{kDa}$. Lectins are versatile in their recognition of glycan-specific structures present on cell surfaces-an interaction-that leads to cell signaling in biological functions $[15,19]$. Each lectin polypeptide contains many molecular domains, one of which is the noncatalytic carbohydrate recognition domain (CRD), called lectin domain. Lectin domain is responsible for its ability to recognize and interact with specific glycoconjugates, without altering their structure. Lectin domains have been studied most intensively in the plant kingdom [15, 19]. CoV-2 infection is the result of interactions between the carbohydrates, present on CoV-2 and receptors such as ACE2 (a lectin) present on host cells such as in lungs or intestine. The reverse interactions can also occur in certain instances.

\section{Angiotensin-converting enzyme 2 (ACE2)}

ACE2 is an integral membrane type 1 glycoprotein, which is an important component of Renin-Angiotensin-System (RAS). ACE2 is an active homologue of ACE present in a diverse community of tissues. During viral infection, the first step is the introduction of viruses into host cells (Fig. 1). This is achieved by binding to the unique receptors (as ACE2) on the host cell membrane to the spike (S) glycoprotein on the viral envelope of CoV-2. Studies have revealed that ACE2 is a functional SARS-CoV receptor [20-25]. Like SARS-CoV, Zhou et al. demonstrated that SARS-CoV-2 is capable of entering ACE2-expressing cells, but not ACE2free cells or cells that express other coronavirus receptors, such as aminopeptidase $\mathrm{N}$ [23].

\section{ACE2 and renin-angiotensin system (RAS)}

The RAS, also known as renin-angiotensin-aldosterone system (RAAS), plays a physiological role in maintaining blood pressure and electrolyte-fluid homeostasis and influencing the functions of many vital organs, including the heart, blood vessels, and kidneys. The RAS acts through two routes: “(1) ACE/angiotensin II (Ang II)/Ang II type 1 (AT1) receptor axis and (2) ACE2/angiotensin (1-7) Mas (mitochondrial 
assembly 1) receptor axis" [16, 26] (Fig. 2A). RAS impairment is linked with the occurrence of acute lung injury (ALI) and ARDS, resulting in poor prognosis and even death [6]. In a variety of pathological conditions, RAS is criti$\mathrm{cal}$, and ACE2 is the central component of the counter-RAS mechanism in both progress and defense of the disease.

The primary function of ACE2 is to metabolize Ang II and to form heptapeptide angiotensin-(1-7), which binds to the Mas receptor (Mas-R). Mas-R mediates vasodilatory, antiproliferative and antifibrotic effects in the pulmonary system. In its chemical action, ACE2 can remove carboxyterminal phenylalanine from Ang II to form the heptapeptide angiotensin-(1-7). Furthermore, under alternating effects of ACE2 and ACE, angiotensin-(1-7) is formed without Ang

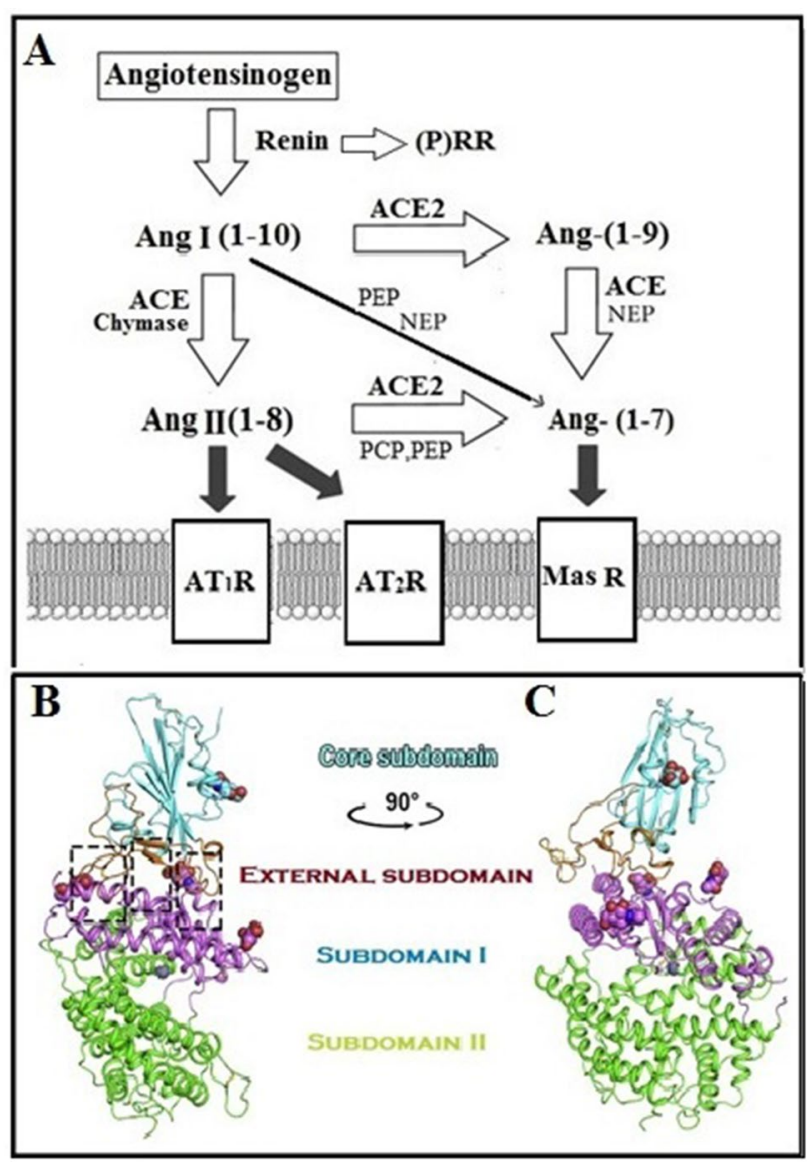

Fig. 2 A The metabolic pathway showing two axes of RAS system: (1) "Classical RAS ACE-Ang II-AT1 regulatory axis" and (2) "ACE2-Ang-(1-7)-Mas counter-regulatory axis." Abbreviations: (P) RR, (pro) renin receptor; Ang, angiotensin; ACE, angiotensinconverting enzyme; ACE2, angiotensin-converting enzyme 2; NEP, neutral endopeptidase; PEP, prolyl endopeptidase; PCP, prolyl carboxypeptidase [3]. B Structure of S CTD-human ACE2 Complex: The core subdomain and external subdomain in SARS-CoV-2CTD are colored cyan and orange, respectively. hACE2 subdomains I and II are colored violet and green, respectively. The right panel was obtained by anticlockwise rotation of the left panel along a longitudinal axis [PDB:6LZG]. Courtesy Wang et al. [7]
II. In this process, Ang I is first hydrolyzed by ACE2 to form angiotensin-(1-9), which is hydrolyzed to form angiotensin-(1-7) by ACE. Angiotensin-(1-7) binds to the G-proteincoupled receptor Mas as a ligand, which causes the opposite reaction to that of Ang II, and performs a number of functions in different organs/systems [26].

COVID-19 depends on host-sex, age-related uncontrolled inflammatory responses, which result into hypercytokinemia, sever inflammation, and collateral tissue damage or systemic failure possibly due to imbalanced ACE/Ang II/AT1R and ACE2/Angiotensin-(1-7)/Mas- $\mathrm{R}$ axes signaling [21].

\section{ACE2: a receptor of coronaviruses}

ARDS is the common immunopathology for different $\mathrm{CoV}$ infections [20, 21]. Molecular similarities have been found in the receptor-binding domains of $\mathrm{CoVs}$, all of which bind the ACE2 receptor, thereby entering the host cells to cause infection. Though several CLRs bind CoVs, ACE2 is the main receptor for the CoV-2 [13-16, 21]. After the virus enters the host cells, the viral RNA is released into the cytoplasm and the viral genome begins to replicate. It is not known definitively whether organs other than the lungs are directly targeted by SARS-CoV-2.

As stated above, $\mathrm{CoV}$ entry in human cells is facilitated by spike (S) protein located on the surface of viral envelope [6]. Host proteases normally divide S protein into two subunits, $\mathrm{S} 1$ and $\mathrm{S} 2$, which are responsible for receptor recognition and membrane fusion, respectively. Both, N-terminal domain (NTD) and C-terminal domain (CTD) of Coronavirus $\mathrm{S} 1$ can act as a receptor-binding (RBD) domain for ACE2 (e.g., SARS-CoV and MERS-CoV utilize S1 CTD, whereas mouse hepatitis CoV engages S1 NTD as RBD) (7).

ACE2 is a transmembrane class I membrane protein exposed to the surface of cells in the lungs and other tissues with its enzymatically active domain. An enzyme known as sheddase [16] cleaves the extracellular ACE2 domain from the membrane. ACE2 also possesses a M2 domain of $\mathrm{N}$-terminal peptidase and a renal amino acid transporter domain of C-terminal collectrin. ACE2 and TMPRSS2 are most richly expressed in bronchial transient secretory cells among diverse cell types in respiratory tissues [16]. After infection of cells with $\mathrm{CoV}-2$, ACE2 is internalized and its expression is downregulated [24, 25]. The function of RAS is uncontrolled resulting in release of several cytokines and chemokines, causing cytokine storm and severe ALI/ARDS.

Wang et al. characterized the ACE2 interaction with SARS-CoV-2 in the intestine. Despite the abundance of ACE2 on intestinal epithelial cells, the occurrence of intestinal symptoms was low, suggesting the role of the innate defense mechanism [25]. Instead, Wang et al. identified a human defensin 5 (HD5), secreted by Paneth cells to bind 
ACE2 and subsequently weaken recruitment of SARSCoV-2 spike protein S1 [27].

\section{Tissue distribution of ACE2}

The ACE2, TMPRSS2, and $C T S B / L$ genes and their proteins are widely expressed in human tissues and the ACE2 and TMPRSS2 genes seem to be co-regulated [8]. In addition to cells in the respiratory system, ACE2 is found in various tissue groups, including gastrointestinal tract, blood forming organs, liver, kidney, brain, and endothelial cells, with the majority identified in enterocytes, tongue, and esophageal epithelial cells. Eyes, male reproductive cells, type II lung alveolar epithelial cells, bladder urothelial cells, endothelial cells, and cardiomyocytes, endothelium of oral and nasal mucosa, nasopharynx also contain the critical viral-entry of ACE2. However, ACE2 mRNA is found in almost every organ [21-23].

\section{ACE2 in obese, diabetic, and hypertensive patients}

The expression of ACE2 in Asians is similar to that in other races [24]. SARS-CoV-2 metabolic comorbidity findings show that obese individuals are more likely to experience infection because adipose tissue acts as a source of pathogenic agents. Due to persistent glucose recognition by ACE2, a greater inflammatory mechanism is seen in diabetic individuals [20, 21, 26]. Patients with hypertension treated with ACE2-inhibitors and ARB have improved expression of ACE2 and are more prone to SARS-CoV-2 cell entry. The ACE2 and TMPRSS gene expressions are suppressed by TNF and are induced by pro-inflammatory conditions including obesity, diabetes, autoimmune diseases, and by oxidized LDL, exercise, cigarette smoke, interferons, and androgens, by growth factors as well as helicobacter pylori and viruses' infections [8].

\section{Innate immune system}

Innate immunity refers to nonspecific defense processes that come into action in the body within hours of the presence of an antigen. For the identification and removal of toxins, the innate immune system serves as the first responder. A variety of distinct molecules participate in the innate immune system in identifying foreign agents by structures seen on their surface, the so-called pathogen-associated molecular patterns (PAMPs). Cell-associated receptors (pathogen detecting receptors, PRRs) or soluble pathogen-recognizing molecules are recognition molecules (PRMs). sMBL is one of the PRPs/PRMs, which, owing to its potential to bind to microorganisms, draws particular interest [15], contributing to the act of opsonin and the activation of the complement system. For the production of therapeutics, understanding the immune response to SARS-CoV-2 is important. The degree to which innate immunity confers protection or induces pathogenesis during SARS-CoV-2 infection via a dysregulated immune response remains unknown [28, 29]. Defects in the innate immune system are responsible for infection or autoimmune disease.

\section{Cells and molecules of innate immunity}

The primary cells in the immune system are leukocytes. They are derived from the myeloid or lymphoid lineage, which contain highly motile neutrophils, monocytes and tissue macrophages, eosinophils, and natural killer (NK) cells. Innate immune cells prevent virus replication by secreting pro-inflammatory cytokines, activating the adaptive immune response, and attracting other immune cells to the site of infection. In response to extracellular pathogens, granulocytes are degranulated and secrete enzymes and toxic proteins. Monocytes traffic to tissues and differentiate into monocyte-derived macrophages and dendritic cells (DCs). At the site of tissue injury, neutrophils emerge first and release the granules to regulate bacterial growth. Macrophages and neutrophils kill pathogens as well as infected cells by phagocytosis. While function of activated DCs is to present pathogen-derived antigens to naive helper $\mathrm{T}$ cells and to initiate the adaptive immune response, NK cells are responsible to destroy infected cells via receptormediated apoptosis and antibody-dependent cell-mediated cytotoxicity.

By producing certain innate cytokines, especially type 1 interferon (IFNs), and by reacting to these cytokines to create new intracellular mechanisms for managing infections, virtually all myeloid lineage cells contribute to innate immunity. Macrophages and DCs possess PRRs that react to PAMPs structures present on infectious agents. Alveolar macrophages in the lungs, histocytes in connective tissue, Kupffer cells in the liver, mesangial cells in the kidney, osteoclasts in the bone, and microglial cells in the brain are macrophages that regulate innate immunity. Relevant molecules, such as chemokines or Fc receptors, may express each subset of macrophages. During immune reactions, chemokines play a significant role in cell trafficking. Chemokine mediators recruit monocytes to the infection site and are critical for innate immune functions to be triggered.

In chemokine family, the chemokine monocyte chemoattractant protein 1 (MCP-1) is a potent chemoattractant for monocytes and macrophages, which secrete pro-inflammatory cytokines/mediators including IL-1, IL-6, IL-8, IL-12, and TNF- $\alpha$ in response to bacterial products. While IL- 8 engages in local inflammatory responses to recruit neutrophils at the site of infection, TNF- $\alpha$ is the inducer of inflammatory responses against pathogens. 


\section{NK cell activity in antiviral immunity and inflammation}

NK cells are the founding members of the innate lymphoid system. They are effector lymphocytes that control microbial infections and their expression besides control of several types of tumors. NK cells are present in most of the human tissues and carry receptors in the form of activating and inhibitory receptors [28]. Peripheral blood, lungs, uterus, and liver are shown to have a high frequency of NK cells, while NK cells are rare in lymph nodes and tonsils and in certain other peripheral organs. NK cells have been extensively studied in different settings of infectious diseases due to viral infections and cancers [30-34]. IL-12 may activate NK cells. The balance of force between activating and inhibitory receptors helps to protect normal cells from the damaging effects of NK cells while killing virus-infected target cells. NK cells can be activated by IL-12. These receptors' balance of force serves to shield normal cells from the harmful effects of NK cells while killing target cells infected with viruses. Infection or autoimmune illness is responsible for defects in the innate immune system.

\section{Complement system}

The complementary system forms an essential part of the innate immune system, and plays a role in immune cell recruitment, activation, and destruction of pathogens [28, 29]. An overactive innate immune response, despite these essential antiviral functions, may lead to disease pathogenesis [15]. In Sect. 8.1, the three complementary pathways that function against pathogens are discussed separately.

\section{Serum mannose-binding lectin}

Serum mannose-binding lectin (sMBL) is a PRP/PRMs that draws particular interest [15] in microbial pathology due to its capacity to bind microorganisms and its role in the activation of the complement system [15]. Serum MBL was discovered in the serum of rabbits as mannose-binding lectin (MBL), which was later termed mannan-binding protein (MBP). The term MBP unfortunately implies a more selective reactivity than the characteristic for this protein. Hence, the term sMBL, which was originally described, will be used in this review.

The explosion of sMBL studies began after discovery of low levels of sMBL and its correlation with the loss of opsonizing activity in infants with unexplained cause of infectivity [35, 36]. Innate and antigen-presenting roles of blood myeloid DCs [35] are affected by sMBL deficiency. It interferes with the entry of $\mathrm{CoV}$ and binding of S protein to host receptors $[9,10]$ and triggering of a downstream antiviral innate immune response. $\mathrm{N}$-linked glycosylation plays a critical role in the specific interaction between $\mathrm{SMBL}$ and SARS-CoV S1 protein.

\section{Structure-function relations of SMBL}

The sMBL is an oligomeric protein with varying molecular weight between 400 and $700 \mathrm{kDa}$, containing three equivalent peptide chains of $32 \mathrm{kDa}$ subunits [37, 38]. Four distinct regions of $s M B L$ gene define the human sMBL molecule: a cysteine-rich amino-terminal region, a collagen repeat domain, a short $\alpha$-helical coiled-coil domain, the so-called neck region, and a CRD that forms the molecule's globular head. The trimeric form is the essential structural subunit of all the sMBL circulating forms [35, 39].

Although sMBL can form multiple oligomeric forms, there are signs that dimers and trimers are not biologically active and that the activation of the complement requires at least a tetramer form. Determined as the holmium-substituted complex, the crystal structure of the CRD of a rat MBP shows an odd fold structure which consists of two different regions, one of which comprises an extensive nonregular secondary structure stabilized by two holmium ions. The arrangement shows the retention of 32 residues, indicating that the sMBL-CRD fold is prevalent in all C-type lectin domains [40].

The triple helix of MBP peptides, the basic structural unit of MBP, aggregates into higher-order structures (tetramers, pentamers, and hexamers), which are required for complement fixation. Through interactions of the collagenous tails stabilized by disulfide bonds in the cysteine-rich aminoterminal region, MBP forms a trimeric helical structure. These trimers combine to produce three or six trimers in a "bouquet" assembly (Fig. 3A).

Each CRD is distanced at approximately $53 \AA$ in the trimer, which is crucial for lectin function. This is because, for glycan ligands, each individual CRD has a relatively low affinity and low specificity and can bind to $\mathrm{N}$-acetylglucosamine, $\mathrm{N}$-acetylmannosamine, fucose, and glucose-rich glycans. Control is given by the spacing between CRDs and enhances possible interactions with extended glycoconjugates containing mannan, especially those on bacteria, yeast, and parasites.

There is a CRD and neck domain in the trimeric fragment of MBP-A. Neck domain connects the carboxy-terminal CRD to the collagen-like structure in the intact molecule $[41,42]$. X-ray crystallography revealed that the neck area consists of a parallel triple-stranded coiled-coil of $\alpha$-helices connected by four residues to the CRD. Neck peptide helixes are not stable in the aqueous phase.

Sequence alignments of lectins suggested that other C-type lectins have a common oligomeric structure with variations in their detailed organization for carbohydrate interactions [41, 42] (Fig. 3B). The spatial arrangement of 


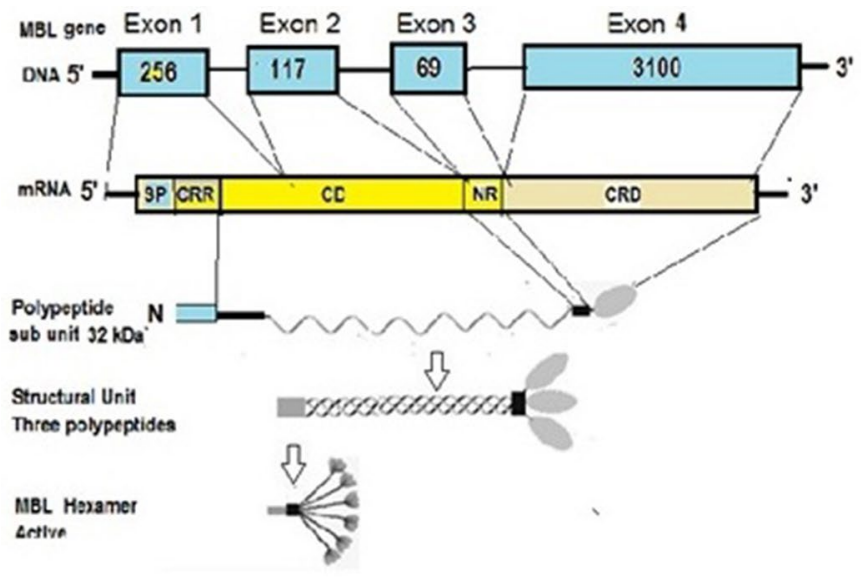

A

Fig. 3 A Human sMBL gene: The human sMBL gene with the corresponding mRNA and protein domains: The lengths of the four exons and three introns are indicated by the number of base pairs in the box of the figure. The mRNA encodes the various protein domains shown as signal peptide (SP), cysteine-rich region (CRR), collagen domain (CD), neck region (NR) (coiled-coil), and carbohydrate recognition domain (CRD) in the figure. The peptides

CRDs of MBP trimers forms the basic recognition domain for oligosaccharides on microbial pathogens.

\section{Clinical manifestations of sMBL deficiency}

\section{sMBL deficiencies are implicated in infectious diseases}

Human sMBL is an important factor in animal defense system that allows us to fight various pathogens by direct neutralization and inhibition. In an indirect role, sMBL acts as an opsonin and as a factor in complement activation [43]. Normal serum sMBL concentration varies from very low level to $10.0 \mathrm{ng} / \mathrm{mL}$. Numerous studies have reported that deficiencies in blood sMBL are associated with several diseases [43-48] at higher risk as invasive pneumococcal disease, infections due to influenza A virus, and at greater risk of death from pneumonia. On the other hand, sMBL showed a significantly higher incidence of influenza (H1N1)pdm09 virus infection in non-survivors of the disease.

Infections of Staphylococcus aureus, Pseudomonas, and recurrent Clostridium difficile are associated with lower sMBL levels in individuals [45]. Humans with recurrent sinusitis are associated with low levels of MBL [46]. Owing to extreme sepsis and septic shock, most patients in the intensive care unit (ICU) are destined to death. Tuberculosis and sepsis patients have significantly low levels of sMBL, whereas neonates with lower sMBL levels have a greater risk of contracting neonatal sepsis $[47,48]$. In about self-associate into a homotrimer (structural subunit). Each peptide contains a lectin domain (gray) to bind the specific microbial carbohydrate motifs. Functional sMBL circulates in higher-order multimers: (tetramers, pentamers, and hexamers) [35]. B Human sMBL (or MBP) carbohydrate recognition domain (CRD) trimerizes through a triple $\alpha$-helical coiled-coil [PDB:1HUP]. Courtesy Sheriff et al. [41]

$30 \%$ of humans, point mutations in the $s M B L$ gene (sMBL2) are responsible for low sMBL activity. As a result, more frequency of infection has been reported in sMBL-deficient patients. Point mutations in the sMBL gene (sMBL2) are responsible for the low activity of sMBL in about $30 \%$ of humans. As a result, sMBL-deficient patients have documented a higher incidence of infection. The exact effect of this type of inherent immune suppression on the clinical outcome of SARS-CoV-2 infection is not clear. Genetic studies on the $s M B L$ gene in complications during infections are of great scientific interest.

In a contrasting study in humans, at influenza diagnosis within 24-48 h following ICU admission, sMBL showed significantly higher levels $(3741 \mathrm{ng} / \mathrm{ml})$ in non-survivors of severe (H1N1)pdm09 infection compared to survivors $(215 \mathrm{ng} / \mathrm{ml})$, as well as in the control group $(1814 \mathrm{ng} / \mathrm{ml})$. The results showed a strong relation between sMBL levels and mortality in ICU patients beyond baseline of $1870 \mathrm{ng} /$ $\mathrm{ml}$ in serious infection $[49,50]$. Liu et al. proposed that sMBL in combination with C-reactive protein may serve as an inflammatory marker in the diagnosis of patients with community-acquired pneumonia [44]. After infection with SARS-CoV-2, the real impact of this type of innate immune enhancement is not clear.

\section{sMBL deficiency in autoimmune diseases}

sMBL deficiency is also associated with noninfectious diseases and with the pathogenesis of autoimmune diseases such as SLE (systemic lupus erythematosus), RA 
(rheumatoid arthritis), and CF (cystic fibrosis). Genotype analysis of RA and primary Sjögren's syndrome [51] patients showed lower MBL levels. The sMBL deficiency can affect or alter the natural history of a disease (e.g., rheumatoid arthritis, cystic fibrosis). Recombinant MBL or plasma MBL treatment is yet to be tried and found safe [51]. sMBL deficiency can affect or change the disease's natural history (e.g., RA and CF) [51]. In practice, sMBL therapy may be a disease-modifying drug to minimize the severity of RA and to protect the function of the lungs and liver [52].

Dong et al. indicated that sMBL levels in patients with arthritis are negatively correlated with the serum levels of markers of bone turnover [53]. sMBL therapy may ameliorate various immunodeficiency syndromes. However, a potential hazard of sMBL therapy is enhanced complementmediated host damage. sMBL therapy awaits the results of randomized controlled clinical trials [51, 54].

\section{sMBL deficiencies and noninfectious diseases}

The worst prognosis with extreme sepsis/septic shock tends to be linked to low-producer haplotypes in critically ill patients. However, as seen in inflammatory disorders, such as diabetic nephropathy and in Covid-19 patients, prolonged stimulation of the innate immune system tends to be responsible for an unbalanced inflammatory and coagulation response [55]. Children with mutations in $M B L 2$ gene resulting in low levels of sMBL have a higher chance of neurological disorders [56].

Although genetic polymorphisms of MBL were not different between patients and control subjects, MBL serum concentration as well as MBL complex activity was significantly higher in new-onset diabetic patients compared with their siblings matched for high-producing MBL. It appears that MBL serum concentration and complex activity are increased in early-onset diabetic patients. [57]. Therapeutic MBL pathway blockade during and following islet autotransplantation (IAT) may improve islet survival and function and thereby clinical outcome.

Deficiency in sMBL is associated with bronchiectasis of noncystic fibrosis, a disease of weakened bronchial passages. While a large variety of diseases has been identified with low serum sMBL levels and their cognate haplotypes, most subjects with sMBL deficiency remain safe. In COPD, reduced serum levels of sMBL are found with greater severity [58] and elevated inflammation in patients with renal function. Renal patients with elevated levels of sMBL have better cardiovascular protection.

Ovarian cancer patients are associated with sMBL deficiency, as determined by genotype. Less artery elasticity [59] is followed by higher pulse wave velocity. Following traumatic brain injury, higher sMBL levels are associated with greater repair. Generally speaking, sMBL has anti-cancer effects. SMBL binds to tumors in patients with colon cancer in an effort to repair the tissues, as tumor patients with binding sMBL have a more promising prognosis [60]. As determined by genotype, ovarian cancer patients are related to $\mathrm{MBBL}$ deficiency.

An estimate indicates that in SMBL, $7-30 \%$ of the western human population is deficient (US 7-10\%, UK 10-30\%). Smoking, second-hand smoke emission, and exposure to solid cooking fuel emissions decrease the levels of sMBL [61]. A research by the Royal Adelaide Hospital in Australia found that elevated levels of oxidative stress decreased sMBL levels by oxidation, oxidizing the lectins (oxMBL). MBL oxidation caused defective macrophage activity that diminished patients' capacity to combat their lung infections [58].

On account of smoking and exposure to carbon monoxide produced during cooking with solid fuel, oxMBL induces higher amounts of oxidative stress [61]. A strong association between healthier lifestyles and higher levels of MBL has been shown. It also appears that diet also has influence on sMBL, since diet produces more antioxidants, alkaline diets are known for their capacity to suppress oxidation within the body. Acidic diets, on the other hand, will, by necessity, reduce the sMBL of the body.

Vitamin D is a promising therapeutic agent since it plays a significant role in the regulation of cardiovascular diseases, in addition to functioning on the immune system. In girls, the levels of sMBL are lower in winter and higher in summer [43]. In the human population globally, these findings need to be checked on a broader scale.

\section{sMBL genotyping and genetic polymorphisms}

Research into the genetic susceptibility of serious infections leading to systemic complications is growing, particularly where the adaptive immune system is weakened, and innate immunity plays an important role in the immediate protection against invasive pathogens. Allelic knowledge involves coding for frequently studied loci, such as MBL $[62,63]$ and CD14. However, some contrasting results have been obtained in relatively limited trials, especially for MBL [64] and DC-SIGNR [65]. But wing to the possibility of an unbalanced pro-inflammatory response and an additional host injury, an accumulation of MBL activation may be dangerous [44, 49].

Tu et al. suggested that people who are genetically predisposed to generate higher levels of MCP-1 protein tend to be more vulnerable to SARS-CoV infection, supporting previous observations that a susceptibility factor for SARS acquisition is a low-MBL-producing allele. The mixture of MCP-1 and MBL polymorphisms has a greater genetic interaction with SARS-CoV infection susceptibility $[63,66]$. 
Many studies on genotyping have emerged due to the ease of allotyping. Although valuable results can be drawn from such studies, it should be recognized that individuals with identical genotypes can vary by several fold in SMBL levels for all known variants of sMBL [35, 67-71]. Since the sMBL2 gene is home to a complex genetic mechanism related to infectious disorders, it is possible that in some diseases, sMBL will also be a disease modifier. Humans have been shown to be vulnerable to infectious diseases caused by single nucleotide polymorphism (SNP) [35, 69-71] due to reduced serum sMBL.

The collectin family is a prominent example among lectin categories [72-75]. A number of infectious and noninfectious diseases have been associated with variant alleles influencing the expression and function of proteins, most often as disease modifiers [68, 72]. Although sMBL influences macrophage responses and contributes to inflammation resolution, SP-A is important for macrophage tissuerepair functions.

The $s M B L 2$ gene is located in the long arm of chromosome 10q11.2-q21 [74]. A large proportion of human population is associated to MBL deficiency due to MBL2 polymorphisms, and susceptible to infectious diseases. Five functional SNPs, in different populations, have been identified in the $s M B L 2$ gene. Each of them can affect serum levels of sMBL. Two SNPs are located within the promoter region of the gene (at -550 and at -221) [70] and 3 other SNPs present at the first exon of the coding region (Fig. 3A). These functional polymorphisms of the sMBL2 gene result in single amino acid substitutions that by inducing structural defects in the SMBL protein, decrease functional levels. The replacement of arginine with cysteine at codon 52 (allele D), glycine with aspartic acid at codon 54 (allele B), and glycine with glutamic acid at codon 57 (allele C) [69] are three separate point mutations.

Codon variants 54 and 57 disrupt the Gly-X-Y repeats in the collagen-like domain and codon 52 disrupts the N-terminal disulfide bonds between structural units of the primary $32 \mathrm{kDa}$ MBL. As a result, the development of the tertiary structure of sMBL $[35,76]$ is prevented by these variants. The assembly of the sMBL oligomeric complexes is disrupted by these three mutations. The role of SMBL in susceptibility to various diseases is controversial, however, and results of interaction for the same diseases depend primarily on the ethnicity of the subjects [77].

Polymorphisms of the MBL gene, a greater prevalence of haplotypes in SARS patients, are associated with low sMBL levels than in control subjects. However, there was no link between genotypes of MBL that were associated with deficient levels of sMBL and SARS mortality. Even then, C4 deposition was increased by MBL in SARS-CoV patients. These findings indicate that MBL is a susceptibility factor for the acquisition of SARS [62] in the first-line of host defense against SARS-CoV. A greater risk of vulvovaginal candidiasis-Candida vagina infections [67] is also associated with MBL2 mutations. Based on MBL genotypes (codon 54 polymorphism), postmenopausal women with lower MBL levels have a higher risk of hypertension and insulin resistance [67].

\section{SMBL suppresses TLR2 activation and inflammatory responses}

Bacterial cell wall peptidoglycan (PGN) is known to induce excessive pro-inflammatory cytokine production. Studies have shown that TLR2 recognizes PGN and that SMBL is capable of suppressing the amplification of inflammatory cytokines in THP-1 cells, including TNF- $\alpha$ and IL-6 [78]. Thus by modulating PGN/TLR2 signaling pathways, sMBL can decrease inflammation and foster a significant function in immune regulation [78].

\section{SMBL is a suppressor of T-cell activation and T-cell proliferation}

sMBL suppresses T-cell activation and greatly prevents T-cell proliferation in presence of anti-CD3 and anti-CD28 antibodies. Moreover, proximal T-cell receptor signaling was interfered by sMBL during T-cell priming. Since sMBL binding to $\mathrm{T}$ cells takes place by interaction between the collagen-like region of sMBL and calreticulin (CRT), expressed on the T-cell surface, the sMBL-mediated inhibition of T-cell proliferation was abrogated by the neutralizing antibody of CRT. This indicated that through cell surface CRT, sMBL downregulates T-cell proliferation. Other serum collectins (e.g., C1q and collectin-11) share this role of sMBL-mediated T-cell suppression. The recruitment and proliferation of autoreactive $\mathrm{T}$ cells derived from patients with silicosis was also effectively inhibited by sMBL, suggesting that sMBL acts as a negative regulator of T-cell responses [79]. sMBL attenuates LPS-induced maturation of monocyte-derived DCs and pro-inflammatory cytokine (IL-12 and TNF- $\alpha$ ) development, suggesting that by altering LPS-induced cellular responses, sMBL affects the functions of DCs. It also supports the essential role of sMBL in the control of inflammatory responses and adaptive immune responses [80].

\section{Role of NK cells and their regulation by SMBL}

NK cells are part of innate immune cells that play a critical role in the first-line of defense against microbial infections as well as in tumor surveillance and their functions in disease progression [33, 34]. NK cells rely on cytokines such as 
'IL-2, IL-12, IL-15, and IL-18' secreted by other immune cells and on other modulators for proliferation and effector functions [81-83]. NK cells develop many chemokines following activation, such as CCL3, CCL4, CCL5, and cytokines such as interferon- $\gamma$ (IFN- $\gamma$ ), TNF- $\alpha$, and colonystimulating granulocyte/macrophage factor (GM-CSF) [82]. These soluble factors play important roles in hematopoiesis and in the activation of cellular networks.

Following activation, NK cells produce several chemokines, such as CCL3, CCL4, CCL5, and cytokines, such as interferon- $\gamma$ (IFN- $\gamma)$, TNF, and granulocyte/macrophage colony-stimulating factor (GM-CSF) [82]. These soluble factors are important in process of hematopoiesis, and in the activation of cellular networks. Serious COVID19 patients suffer with lymphopenia and elevated plasma levels of IL-6. Though the expression of NKG2D (a NK cell receptor) is critical in destroying infected cells [84-87], IL-6 inhibits NKG2D expression and does not allow NK cells for normal functioning. Several upregulated genes in peripheral blood mononuclear cells (PBMCs) from COVID-19 patients tend to be implicated in apoptotic pathways, suggesting that lymphopenia is due to apoptosis induced by SARS-CoV-2 [88]. Other studies indicate that NK cells leave the peripheral blood and traffic into the lung following SARS-CoV-2 infection, where they possibly lead to local inflammation and injury. NK cells remaining in circulation, on the other hand, exhibit an exhausted phenotype that promotes the dissemination of viruses to other organs [32].

\section{Reduced NK cells in the blood of COVID-19 patients}

COVID-19 patients have elevated plasma levels of IL-6 with lymphopenia. By reduced expression of NKG2D, which is critical in destroying infected cells, IL-6 can further inhibit NK function [84-87]. Many amplified genes in peripheral blood mononuclear cells (PBMCs) from COVID-19 patients tend to be implicated in apoptotic pathways, suggesting that lymphopenia is due to apoptosis induced by SARS-CoV-2 [87].

Besides lungs, SARS-CoV-2 can infect many other organs, because of the existence of ACE2. Lung NK cells do not, however, express ACE2 as a SARS-CoV-2 feedback receptor [89]. NK cells can also not be specifically contaminated with SARS-CoV-2 [90]. NK cell receptor NKG2A, on the other hand, is elevated in CD8 T and NK cells in COVID-19 patients [91, 92]. NKG2A thus represents another receptor in COVID-19 due to its role in the host's immunity. By the development of IFN- $\gamma$ [85], monalizumab (a humanized $\mathrm{IgG} 4$ ) targeting NKG2A receptors on NK and $\mathrm{CD} 8+\mathrm{T}$ cells could help to restore adequate antiviral activity.

\section{SMBL regulates cytokine production and cytotoxicity of NK cells}

Owing to its association with numerous kinds of immune cells, sMBL has been considered an immunomodulator, and role of sMBL in relation to NK cells remains unexplored, however. In addition to phagocytosis of pathogens by leukocytes and activation of the lectin complement pathway, sMBL can bind to human monocytes and attenuate the inflammatory response [44]. While looking for how sMBL can influence NK cell activity, Zhou et al. suggested that human sMBL could communicate directly with peripheral NK cells through its collagen-like domain [93].

An in vivo study showed that recombinant SMBL administration in mice could control the immune response of the host and that SMBL association with human T cells inhibited the activation of T cells [79]. The sMBL-binding NK cells markedly suppressed the development of IL-2-induced TNF- $\alpha$ and IFN- $\gamma$, inflammatory cytokines, and upregulated production of IL-10. However, the expression of activation markers such as CD25 and CD69 declined after sMBL therapy.

In addition to NK cell proliferation and lymphokine-activated killing, sMBL inhibited the activation of NK cells by IL-2-induced STAT5 (signal transducers and transcription activators 5). Taken together, studies indicate that SMBL is capable of controlling the activity of NK cells and can act as an immune response regulator [93]. Therefore, sMBL is a pleiotropic immune modulator that can influence various cell types of innate and adaptive immunity [93, 94].

\section{Cytokine storm in COVID-19}

COVID-19 patients pass through three major stages depending on infection severity. In step 1, the CoV-2 binds ACE2 receptor present on lung macrophages and epithelial cells where it activates toll-like receptor-mediated NF-kB signaling and silencing of early IFN response that enables controlled viral replication. Phase 2 is discriminated by the presence of hypoxia and damaged pneumocytes due to loss of innate immunity. Some patients advance into phase 3, accompanied by an aggressive inflammatory response, with the release of elevated levels of pro-inflammatory cytokines, a condition known as "cytokine storm syndrome (CSS)," worsening of respiratory symptoms, and hemodynamic instability of the patients. IL- 6 , IL- $1 \beta$, and TNF- $\alpha$ are essential cytokines, besides others, which are released in this process. This, as usual, is followed by production of antibodies against the virus under recovery phase [95]. 


\section{How to define "cytokine storm"}

Cron and Behrens defined "cytokine storm syndrome (CSS) [96] as an activation cascade of auto-amplifying cytokine release due to the uncontrolled host immune response to various triggers, such as in infections, malignancy, rheumatic diseases, etc." In another study, "the cytokine storm was defined as a systemic inflammatory response to infections and drugs that lead to excessive activation of immune cells and the generation of pro-inflammatory cytokines." There is another related term for CSS "cytokine release syndrome" (CRS), which is an acute inflammatory systemic disease marked by multiple-organ dysfunction [97]. The cytokine storm ensures that host cells are injured by the levels of released cytokines [88]. In general, the cytokine storm is believed to include the innate immune system's aberrant reactivity, dysregulated inflammatory responses, and overexpression of inflammatory cytokines. Over-expression of IL-6, in particular, is considered a characteristic hallmark of the cytokine storm. It has been discussed elsewhere how elevated levels of inflammatory cytokines interfere with the complementary and coagulation processes to cause DIC, ARDS, and MOF [98]. A functional characteristic of these cytokines is that they have brief half-lives, usually limiting contact within lymphoid tissues and at inflammatory sites to certain cell types. Cytokines may also have systemic activities at high levels, and colony-stimulating factors generated at sites of microbial invasion can encourage emergency bone marrow granulopoiesis. The presence of elevated levels of cytokines can affect a large variety of physiological processes for those pathogens with systemic involvement. Elevated levels of inflammatory cytokines interfere with complement and coagulation processes to cause DIC, ARDS, and MOF [98]. The cytokine storm is commonly known to comprise the innate immune system's aberrant reactivity, dysregulated inflammatory reactions, and over-expression of inflammatory cytokines. Over-expression of IL-6 is considered a hallmark of the cytokine wind.

\section{Cytokine functions}

In the activation of anti-microbial effector functions, cytokines play a direct role, but they also have regulatory signals that specifically amplify the immune response. These secreted proteins have brief half-lives and usually brief contact within lymphoid tissues and at inflammatory sites to certain cell types. Cytokines may also have systemic activities at high levels. There colony-stimulating factors generated at sites of microbial invasion can activate emergency granulopoiesis in the bone marrow along with increased neutrophil and monocyte development. The presence of elevated levels of cytokines can affect a large variety of physiological processes for those pathogens in systemic involvement. Under enhanced innate recognition or elevated $\mathrm{T}$ cell responses, the inability to overcome can manifest as levels of cytokines in the bloodstream under certain conditions. This situation, demonstrated under clinical conditions, termed as cytokine storm, cytokine release syndrome (CRS), or hypercytokinemia to characterize a number of conditions with varying etiologies and results $[88,98]$.

\section{Cytokine response in COVID-19}

ICU Covid-19 patients have high number of WBCs, neutrophils, and high levels of procalcitonin, CRP, and other inflammatory indices in blood in comparison to non-ICU COVID-19 patients. Many studies have shown that severely ill Covid-19 patients have a high level of blood pro-inflammatory cytokines. The deadly unregulated systemic inflammatory reaction under CSS/CRS conditions have been attributed to the release of massive quantities of pro-inflammatory cytokines such as "IFN- $\alpha$, IFN- $\gamma$, IL-1 $\beta$, IL-6, IL-7, IL-12, IL-18, IL-33, TNF- $\alpha$, TGF $\beta$, etc., and chemokines as CCL2, CCL3, CCL5, CXCL8, CXCL9, CXCL10, etc." by immune effector cells in SARS-CoV infection [99-102], in addition to increased "IL-2, IL-7, TNF- $\alpha$ GM-CSF, IFN- $\gamma$, inducible protein $10, \mathrm{MCP}-1$, macrophage inflammatory protein $1-\alpha$ (MIP-1 $\alpha$ ), and especially IL-6" [101, 102] (Fig. 4), than in moderately ill COVID-19 patients.

The bronchoalveolar lavage fluid (BALF) from SARSCoV-2 infection showed presence of excessive chemokines, such as CXCL10 and CCL2. SARS-CoV-2 triggered immune responses resulted in unregulated inflammatory response of cytokines storm [97]. In this sense, COVID19 shares parallels with other viral diseases such as SARS, MERS and influenza, where the formation of a cytokines storm is a warning sign of an escalation of the disease [97]. In a comparative analysis of different diseases, Kox et al. reported that critically-ill Covid-19 patients do not explain strongly elevated levels of inflammatory proteins in blood, and thus, it raises the question on the definition of 'cytokine storm in Covid-19' [103].

\section{IL-6: a sensitive CSS biomarker}

IL-6 is a sensitive CSS biomarker, which has pleiotropic functions, including hematopoietic regulation, tissue regeneration, chronic inflammation, autoimmunity, and tumorigenesis. COVID-19 serious patients, requiring ventilation, have higher blood IL-6 than patients experiencing only mild symptoms [104-106]. Under CSS/CRS, inflammatory monocytes express high levels of IL-6, starting a localized and then systemic cascade effect that results in hyperproduction of IL-6, which accelerates the inflammatory process. Because IL-6 also increases vascular permeability, excessive levels cause blood vessels to become very leaky. This, along 
Fig. 4 Cytokine storm in COVID-19: A Normal immune response to viral infection.

B Abnormal immunologic response to infection. Courtesy Siemens Healthineers, India [177]
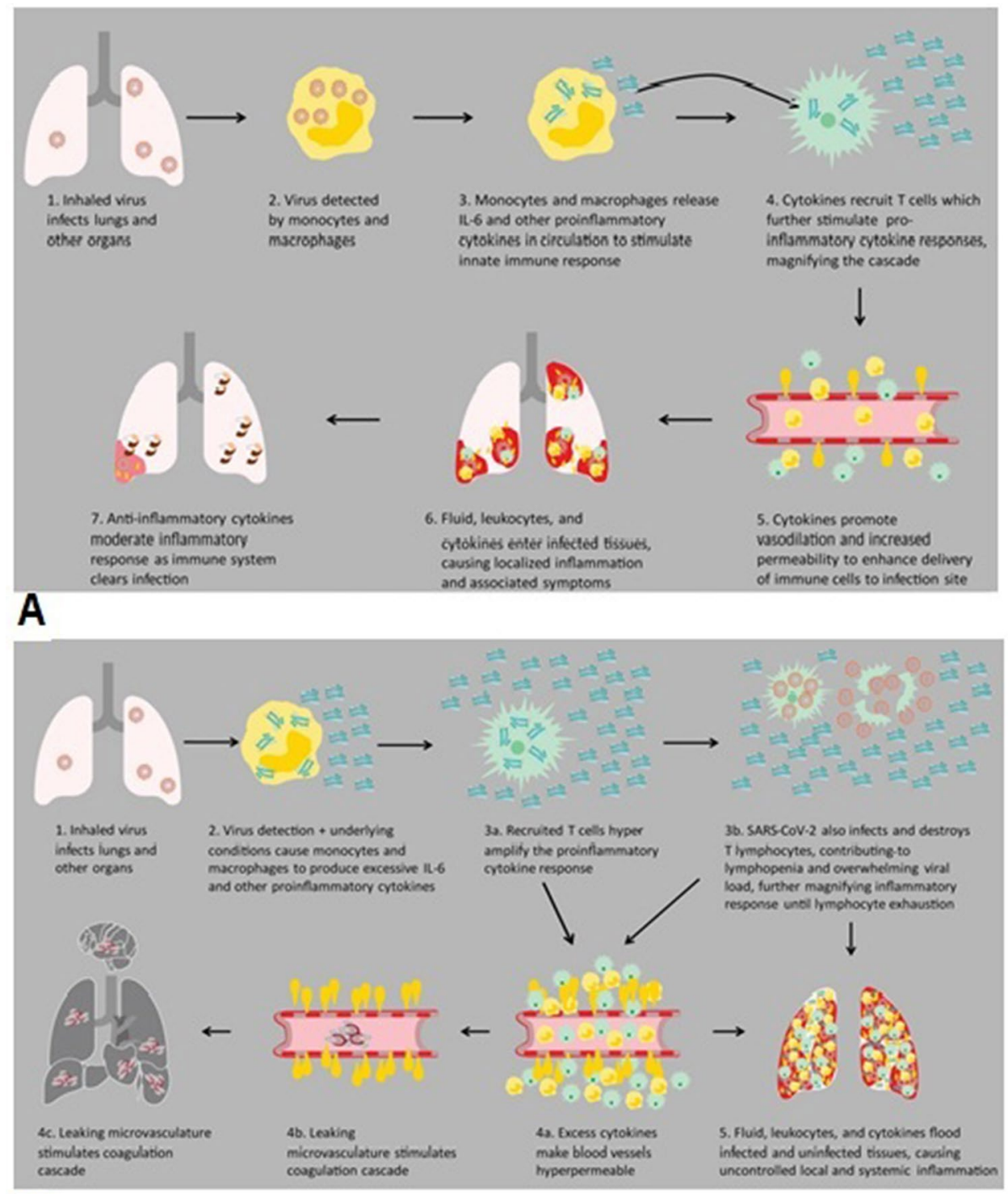

B

with clotting factors released from vascular endothelial cells, stimulates the coagulation cascade, resulting in microthromboses (tiny clots), which lead to ischemia and tissue death of the kidney, intestines, heart, liver, brain, and extremities [104]. While pro-inflammatory cytokines such as IL- $1 \beta$ and TNF- $\alpha$ drive the initial cytokine response, IL- 6 dysregulation is the most profound effect and is the best indicator of CSS severity. Medications blocking the IL-6 pathway have shown encouraging results in therapy of Covid-19 patients. TNF- $\alpha$ may encourage T-cell apoptosis by interaction with its receptor among over-expressed pro-inflammatory soluble factors and may in part lead to lymphocytopenia, a trait frequently seen in COVID-19 with a more pronounced decline in extreme cases.

\section{sMBL in lectin complement pathway}

Bacterial and viral experiments offer parallel insight into the coronavirus-induced complement pathways. The low expression variant of sMBL has been reported as a susceptibility factor for SARS-CoV-1 with contradictory conclusions, as a mediator of pathology [62-66] (see Sect. 8).

\section{Complement activity during COVID-19}

\section{Complement system}

One of the significant mechanisms of innate/natural immunity for host defense against invading pathogens is the 
complement system or complement cascade. Complement is a heat-labile plasma proteinous component, which is responsible killing of pathogens by opsonisation. The complement system has been found to cause immune injury in COVID19 patients. However, despite many therapeutic targets in COVID-19 and its ramifications in the pathophysiology of MERS and SARS, the complement has gained little consideration in looking for successful anti-inflammatory treatment strategies.

There are three pathways of complement that comprise a cascade of $>30$ inactive proteins, which are present in the blood and tissue fluids. The inactive complement proteins, in response to the interaction with molecular structures of the pathogen, are sequentially activated in the form of an enzymatic cascade [107]. The chemical process takes place by sequential cleavage of complement complexes in all complement pathways, followed by the binding of a larger cleavage product to the pathogen and the activation of the next component. In the end, all the complement pathways converge at a point of $\mathrm{C} 3$ convertase (an enzyme), which cleaves $\mathrm{C} 3$ to form the large product, $\mathrm{C} 3 \mathrm{~b}$, and a small fragment, $\mathrm{C} 3 \mathrm{a}$. While $\mathrm{C} 3 \mathrm{~b}$ acts as an opsonin, $\mathrm{C} 3 \mathrm{a}$ acts as an anaphylatoxin that promotes inflammation (Fig. 5).

The main event in complement activation is the binding of significant amounts of $\mathrm{C} 3 \mathrm{~b}$ to the pathogen. Complement receptors which are present on the phagocytic cells are recognized by bound complement components, like C3b. Phagocytic cells ingest and eat C3b-opsonized pathogens and their inactive fragments. These activities aid phagocytes for uptake and demolition of pathogens. The activated C3 ultimately passes through the lytic pathway, which can destroy the membranes of the cells or the pathogen.

C5a, generated in this process, is a chemoattractant that attracts macrophages and neutrophils and can stimulate mast cells. The larger C5b fragment attaches the cell surface and activates the formation of a membrane-attack complex (MAC) - C5bC6789, which is responsible for the lysis of pathogens. The behavior of complement constituents depends on regulatory proteins that save the host cells from unintended damage caused by activated complement components. Deficiencies of an individual component of the system may lead to diseases, indicating role of component in protection against diseases (Fig. 5) [107]. It is initially possible to activate the complement using each of the three separate pathways (Fig. 5) [107].

\section{Classical pathway}

The classical pathway is activated either directly by a pathogen or indirectly by a pathogen-binding antibody. C1, C2, and $\mathrm{C} 4$ are classical pathway components. The pathway is activated by the binding of the antibody-antigen complex to $\mathrm{C} 1$, which exists in three substructures: $\mathrm{C} 1 \mathrm{q}, \mathrm{C} 1 \mathrm{r}$, and $\mathrm{C} 1 \mathrm{~s}$. The pathway results in the formation of $\mathrm{C} 3$ convertase, $\mathrm{C} 4 \mathrm{~b} 2 \mathrm{a}$. The $\mathrm{C} 3$ convertase splits $\mathrm{C} 3$ into two fragments: $\mathrm{C} 3 \mathrm{~b}$, the larger fragment that binds to and opsonizes the microbial surfaces; the other smaller fragment, $\mathrm{C} 3 \mathrm{a}$, that degranulates mast cells that release histamine-like inflammatory mediators [107] (Fig. 5).

\section{Mannose-binding lectin pathway}

Lectin pathway of complement is similar in cascade of reactions to the classical complement pathway. The lectin pathway is activated by SMBL, or ficolin, in conjunction with MBL associated serine protease-1 (MASP-1). The activation occurs after binding of the MBL-MASP-1 complex to the mannose residues present on the surface of the pathogen, and MASP-2. To form the $\mathrm{C} 3$ convertase, $\mathrm{C} 4 \mathrm{~b} 2 \mathrm{a}$, the complex activates $\mathrm{C} 4$ and $\mathrm{C} 2$ (Fig. 5).

\section{Alternative pathway}

The complement's alternate pathway opsonizes and destroys pathogens. The pathway is activated when pathogens or weakened cells are specifically bound by the $\mathrm{C} 3 \mathrm{~b}$ protein. In this process, $\mathrm{C} 3 \mathrm{~b}$ binds to factor $\mathrm{B}$, which is cleaved by factor $\mathrm{D}$ to $\mathrm{Bb}$. The other variables in the pathway that form a $\mathrm{C} 3$ convertase and activate more $\mathrm{C} 3$ are the $\mathrm{H}$ and I (Fig. 5). During critical illness, the alternative pathway amplifies all complement activity and improves survival, likely due to improved immune capacity [108]. Thus, complement is a "dual-edged sword" which is critical for innate immunity against pathogens.

\section{Lytic pathway}

C5 convertase generation results in the activation of the lytic pathway that is triggered by $\mathrm{C} 5$ splitting and $\mathrm{C} 5 \mathrm{~b}$ binding to the target $\mathrm{C} 6, \mathrm{C} 7, \mathrm{C} 8$, and $\mathrm{C} 9$ and formation of MAC. When injected into the membrane of pathogens, MAC causes lysis to destroy pathogens (Fig. 5).

\section{Uncontrolled activation of complement}

Uncontrolled activation of complement leads to many undesired events. Java et al. suggested that CoVs activate multiple complement pathways leading to immunopathies, dysregulated neutrophilia, endothelial injury, and hypercoagulability, intertwined to result in severe features of COVID-19 [109]. The hyper level of C5a produced in acute lung injury (ALI) by influenza viruses and SARS-CoV displays strong activities of phagocytic cells and inflammatory events, which can lead to cytokines storms [110]. Inhibition of C5 blocked 


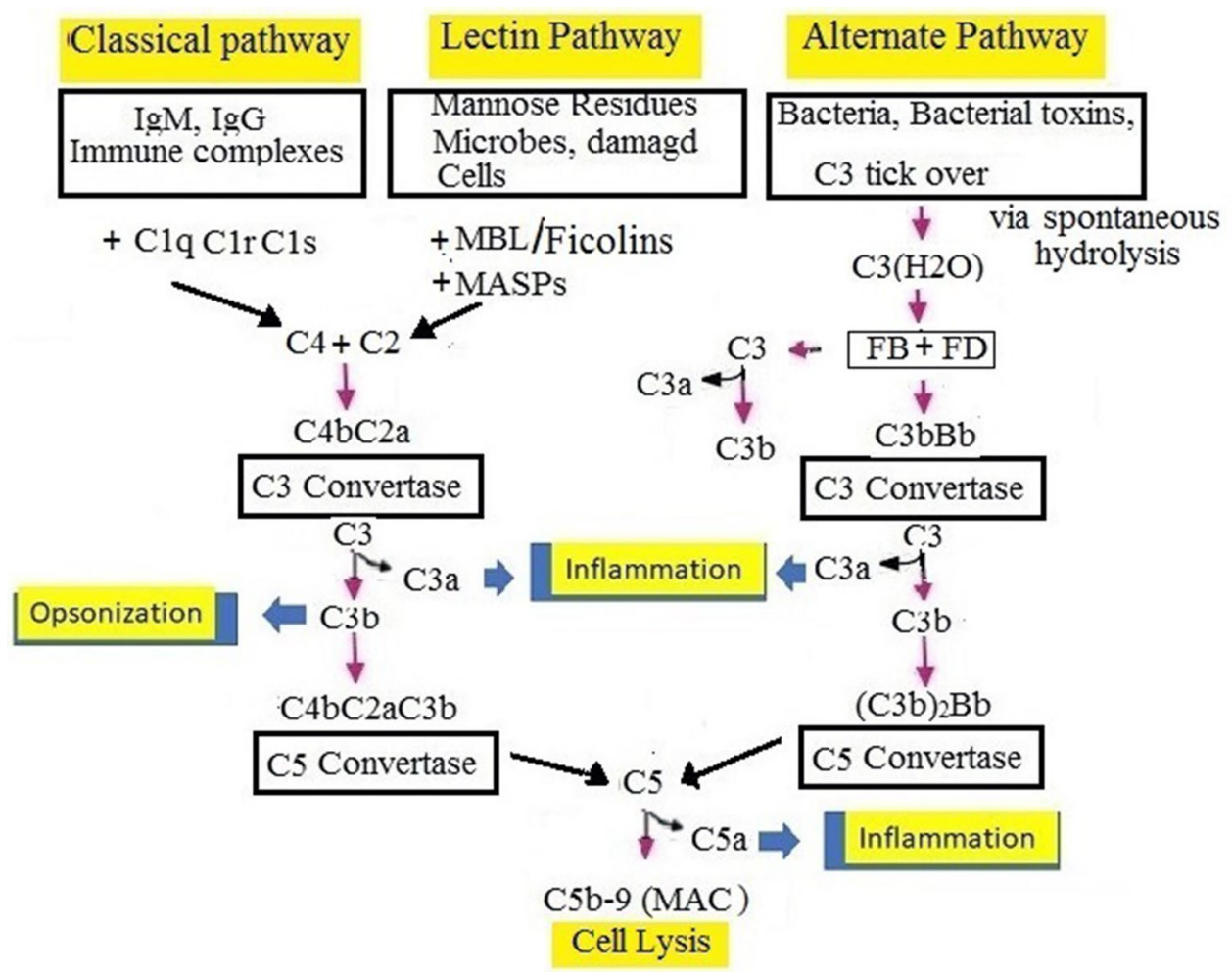

Fig. 5 Description of 3 overlapping-pathways for complement activation: The complement: opsonin $\mathrm{C} 3 \mathrm{~b}$, anaphylatoxins $\mathrm{C} 3 \mathrm{a}$ and C5a (complement peptides), and membrane-attack complex (MAC, C5b-9), produced by all three pathways. (1) In classical pathway, $\mathrm{C} 1$ complex $(\mathrm{C} 1 \mathrm{qC} 1 \mathrm{rC} 1 \mathrm{~s})$ formed from $\mathrm{C} 1 \mathrm{q}, \mathrm{C} 1 \mathrm{r}$, and $\mathrm{C} 1 \mathrm{~s}$ attaches antigen-antibody complexes and results in the development of $\mathrm{C} 2$ and $\mathrm{C} 4$, which form a $\mathrm{C} 3$ convertase $(\mathrm{C} 4 \mathrm{bC} 2 \mathrm{a})$. The latter cleaves $\mathrm{C} 3$ further into $\mathrm{C} 3 \mathrm{~b}$ (an opsonin) and $\mathrm{C} 3 \mathrm{a}$ (an anaphylatoxin). Binding another $\mathrm{C} 3 \mathrm{~b}$ to the $\mathrm{C} 3$ convertase creates a $\mathrm{C} 5$ convertase $(\mathrm{C} 4 \mathrm{~b} 2 \mathrm{a} 3 \mathrm{~b})$. (2) The lectin pathway is similar to the classical pathway, but it is activated by a complex of sMBL-MASPs instead of classical C1 protease complex (C1qC1rC1s). (3) The alternative pathway (AP) is continuously self-activated in plasma by low-grade hydrolysis (tick-over)

LPS release and downstream signaling, over production of inflammatory cytokines, and procoagulant proteins. Therefore, inhibition of C5a is implicated in the treatment of ALI induced by viruses including SARS-CoV-2.

\section{Complement in disseminated intravascular coagulation}

Disseminated intravascular coagulation (DIC) is a pathological condition characterized by an increased incidence of thrombin formation due to the interaction of platelets and coagulation factors in the circulation. Sepsis, which has been speculated to be attributed to overactivation of complement and platelet activity, is the common cause of DIC. Some studies have indicated that SMBL-associated serine protease (MASP-1or -3) is involved in post-injury hemostasis. In addition, complement components are altered of $\mathrm{C} 3$ that forms $\mathrm{C} 3\left(\mathrm{H}_{2} \mathrm{O}\right)$. On pathogen surface or infected tissue, the nondiscriminate tick-over immediately binds factors $\mathrm{B}$ and $\mathrm{D}$ to form a $\mathrm{C} 3$ convertase $\mathrm{C} 3 \mathrm{bBb}$ or $\mathrm{C} 3\left(\mathrm{H}_{2} \mathrm{O}\right) \mathrm{Bb}$ to activate more $\mathrm{C} 3 \mathrm{~b}$. (4) $\mathrm{C} 3 \mathrm{~b}$, which is produced by either of the 3 pathways, opsonizes the target, binds a $\mathrm{C} 3$ convertase to generate $[\mathrm{C} 4 \mathrm{~b} 2 \mathrm{a} 3 \mathrm{~b}$ or $(\mathrm{C} 3 \mathrm{~b}) 2 \mathrm{Bb}]$ trimolecular C5 convertases, and generates more C3b via AP. C5 splits into $\mathrm{C} 5 \mathrm{a}$, which is a strong anaphylatoxin, and $\mathrm{C} 5 \mathrm{~b}$, which initiates the terminal lytic cascade to form the complex membrane-attack complex (C5b-9, MAC). C3a and C5a are potent neutrophil and monocyte chemoattractants. In serious COVID-19 patients, complement activation can lead to the harmful inflammatory response. C3, C5, and MASP-2 may act as therapeutic targets [109, 113, 139-142]

in DIC patients with sepsis and C3, terminal complement complex, and MBL were substantially increased [111, 112]. Lung degradation in Covid-19 patients was not due to elevated viral loads, but it is related to the maladaptive immune response. Another report suggested that PRR activation of lung immune cells is responsible for the release of pro-inflammatory cytokines and unwanted blood neutrophils and monocytes into the bronchi [113]. In severe ARDS, associated CoV-2 infection acute respiratory failure and the systemic coagulopathy are critical events. Under this situation, renal injury is not caused by viral infection. Rather, it arises due to hypercytokinemia and the inflammation that affect diminished oxygen uptake by the lung parenchymal and endothelial cells, resulting in intravascular coagulation and overlap with thrombotic microangiopathies (TMAs). These observations have raised the risk that activation of the complement is a central contributor to the pathogenesis 
of COVID-19 [55]. Quantification of gene expression at RNA level of nasopharyngeal (NP) swab from SARS-CoV2-infected patients demonstrated that in addition to innate Type I IFN and IL-6 inflammatory immune responses, infection results in activation of the complement and coagulation pathways [114]. These studies indicate that a possible alternative for the treatment of multiple-organ failure (MOF) is to block the complementary pathway [55, 114].

\section{Complement system in critical illness}

Biological stressors, including infection, ischemia, trauma, burns, wounds, cancer, and surgery, have all been noted to activate the human complement system. However, it is not known to what degree the complement system provides defense or causes pathogenesis through a dysregulated immune response. It is suspected that overexuberant activation of the complement system, considering its role in immune function, leads to the pathogenesis of sepsis and other critical diseases [115].

Three types of major effectors, produced by the active complement system, have been described above: (1) anaphylatoxins, pro-inflammatory molecules that trigger leukocytes by interacting with their G-receptors; (2) opsonins, which target cell surfaces and help in the removal of target cells and immune complexes; and (3) the terminal membrane-attack complex (MAC, C5b-9) that directly lyses targeted (opsonized) pathogens or damaged self-cells [55, 116]. In host defense against microbial pathogens and in the removal of immune complexes and apoptotic cells, these effectors cause the complement system to play an important role. During last few years, other essential complement functions, including modulation of adaptive immune response and many others have been identified [55, 116, 117]. Functional enrichment analysis of genes in peripheral blood mononuclear cells (PBMCs) of COVID-19 patients showed dominance of genes associated with complement activation of classical pathway [87]. Similar to SARS, complement proteins in serum are higher in severe COVID-19 patients relative to mild Covid-19 patients and healthy controls [118, 119]. Reports suggested that complement plays a potential role during SARS-CoV-2 infection.

\section{Complement activation in ARDS and COVID-19}

A common feature in ARDS, caused by infectious agents, is complement activation and $\mathrm{C} 5 \mathrm{a}$ is elevated in peripheral blood. C5a is an ARDS marker that follows in severe sepsis, cytokines storm, and MOF. PMN, when exposed to C5a, may adhere to vascular endothelium and increase vascular permeability that may lead to ARDS. This results into neutrophilia, which has been reported in COVID-19 [120]. Evidence also suggests that the lectin pathway of complement activation is active in COVID-19 patients. It seems that fucose and mannose residues on $\mathrm{S}$ protein of SARS-CoV-2 are able to activate the lectin pathway by interacting with lectins (Collectin-11 or Ficolin-1), which are expressed in alveolar epithelium and also present in blood circulation [121]. The interaction of SARS-CoV-2 with these lectins in blood may also activate the inflammatory and coagulation cascades in the lung and blood [122]. The presence of "MBL, MASP-2, C4, C3, and C5b-9" has been confirmed in post-mortem lungs of SARS-CoV-2-infected patients with ARDS [64, 117]; the alveolar epithelial cells of type I and type II were the key targets for complement deposition. The presence of MBL and MASP-2 also suggested the role of lectin pathway on alveolar epithelial cells. Elevated serum C5a levels presented evidence of systemic activation of the complement or leakage of the active fragment from the diseased lung.

Co-triggering of the complement and coagulation cascades has been reported in children suffering with COVID19 and having hyper-inflammatory diseases and thrombosis. In COVID-19 patients with respiratory failure, triggered by complement pathway and related procoagulant state [118-120], MASP-2 and viral S protein were found colocalized with C4d deposits $[68,118]$. The presence of elevated d-dimers and purpura in the skin suggested that lung damage in COVID-19 requires more than one mechanism.

The process of overactivation of the complement system worsens lung injury. By comparison, complement activation can occur at the earliest by direct association of viral proteins with the MBL-ficolin pathway, rather than the alternative pathway. Gao et al. observed that the protein SARS-CoV-2 nucleocapsid (N) interacts with MASP-2 and induces autoactivation of MASP-2 and complement protein cleavage, C4 [117]. Furthermore, during the second week of illness, the development of SARS-CoV-2-specific IgM and IgG may further activate the complement system through the classical pathway, while human IgA may activate the complement system through the MBL pathway [113].

Since alveolar epithelium is the primary site of activation of complement after exposure to SARS-CoV-2 and may secrete complement factor including $\mathrm{FCN}-1$ and CL-11, it seems that the primary target for CoV-2 virus is alveolar cells. The formation of C3a, C3b, C5a, and C5b-9, which are pro-inflammatory effectors of complement activation, can be further activated by the presence of FCN-1 and CL-11 and other important proteins of the lectin complement pathway. Furthermore, because macrophages also express ACE2 and generate complement components, the effect of C5a on cytokine release can be exacerbated by viral invasion of macrophages. It is suspected that the circulating viral particles can trigger complement activation through the MBL pathway and cause 
microvascular injury [122]. Microvascular thrombosis could then be predisposed to the procoagulant effects of MASP-1 and MASP-2 in the interaction of C5a and MAC on endothelium, but experiments are required to confirm these hypothetical pathways. To precipitate complement activation by another way, ACE2, present on the proximal tubule epithelium, can also break C3 [122, 123]. Gao et al. indicated that CoVs' secreted nucleoprotein (N protein) binds to MASP-2, the main component of the lectin pathway, which results in activation of complements and exacerbated inflammatory lung injury. $\mathrm{N}$ protein-MASP-2 interaction is thus an effective target for suppressing activation of the complement and alleviating hyper-activation and lung damage of the $\mathrm{N}$ protein-induced complement. When critical patients were treated with anti-C5a mAb, hyper-activation of complement in COVID-19 patients was suppressed [117]. Studies have shown that the relationship between CL-11 and L-fucose results in the activation of complement by the lectin complement pathway by attacking the ischemic tubule surface with an innate immune response.

A study on the MERS-CoV in murine model found that excessive activation of the complement could lead to acute lung injury after infection, while blockade of C5a-C5aR (R: receptor) could reduce lung injury. In addition treatment with anti-C5aR $1 \mathrm{mAb}$ of infected mice resulted in reduced viral replication in lung [117, 124]. A general upregulation of complement proteins, including MAC complex, C5, C6, and C8, was reported by Shen et al. in the SARS-infected mouse model [125] and inhibition of the complement system via immunotherapy. C5a is also highly expressed in patients with extreme SARS and MERS, and its inhibition has been reported to relieve ALI caused by viral infection $[124,126]$.

\section{Complement deposits in lungs of COVID-19 patients}

Presence of complement components in lungs of COVID19 patients indicated that complement protein deposits are responsible for lung injury (Fig. 5) and the MBL lectin pathway played a role in SARS-CoV clearance [62]. MBL genotypes responsible for low sMBL have been found to be the causative factor for SARS [62]. These findings were not, however, compatible with Yuan et al. who demonstrated no discrepancy between SARS patients and normal controls in the MBL genotypes [64].

In SARS-CoV patients, the activation of component $\mathrm{C} 3$ aggravates ARDS caused by SARS-CoV [120, 127]. In support of this, C3-deficient mice infected with comparable SARS-CoV load, displayed reduced respiratory dysfunction and low levels of cytokines and chemokines in lungs and sera [127], indicating that the inflammatory lung symptoms in SARS-CoV-2 patients can be alleviated by $\mathrm{C} 3$ inhibition [113]. Similarly, antibody blockade of the C5aC5aR1 decreased lung damage in transgenic mouse model of MERS-related infection [128]. The sMBL deficiency is therefore associated with an increased vulnerability to a wide variety of infections, especially in children [129-131]. In contrast to serious Covid-19 patients, a small group of health workers infected with mild CoV-2 infection showed low serum $\mathrm{C} 3$, indicating the utilization of $\mathrm{C} 3$ in patient's defense [132]. The exact role of the complement system in the pathogenesis of COVID-19, however, requires further analysis [115].

\section{Role of airway epithelial cells}

In addition to immune cells in lung, airway epithelial cells (ACEs) also assist in host defense against invading microbes by expressing membrane-bound soluble PRRs. Some of these proteins are secreted by AECs (such as MBL, lung surfactant proteins SP-A and SP-D, the complement components $\mathrm{C} 3$ and $\mathrm{C} 5$, pentraxin $\mathrm{C}$-reactive protein, and pentraxin 3; serum amyloid A; H-ficolin) [133-136].

Lung SP-A and SP-D belong to collectin family of lectins. These lectins bind to several microorganisms, resulting in their killing, and enhancing their phagocytosis by alveolar macrophages [73, 74]. SP-A and SP-D are capable of interaction with proteases such as MASP-1, -2 and can trigger the lectin complement pathway. However, MASP-3 can activate the alternative pathway of complement. Further more, MASPs play a role in other processes related to coagulation and platelet activation.

In addition to sMBL, collectin-10, collectin-11, and ficolins (ficolin-1, ficolin-2, and ficolin-3) also participate in the lectin complement pathway and act as mediators of host defense. In order to modulate innate immune functions, Collectin-10, -11 bind to pathogen-specific structures and modified self-antigens and form complexes with pentraxins $[15,68,134]$. The levels of sMBL also influence the production of cytokines and hence the inflammatory response of the host [82]. Pediatric patients with sMBL gene polymorphisms are more vulnerable to developing sepsis and systemic inflammatory response syndrome (SIRS) when combined with low levels of functional sMBL $[48,135]$. More kn'owledge is required for understanding of the role of sMBL in Covid-19's pathogenesis.

\section{MBL-mediated complement activation in systemic disorders}

The lectin pathway of complement and MBL-SNP polymorphisms has been described in diabetic complications ("sMBL genotyping and genetic polymorphisms" section). In diabetic patients, sMBL-mediated activation is impaired, and alternative pathway amplification is lowered during 
bacterial infections [137]. Serum levels of proteins of the sMBL pathway indicate the role of complement-dependent inflammation in the pathophysiology of cardiovascular disease [137]. In post-traumatic brain injury, the presence of components of lectin pathway, C3 fragments inside and outside brain vessels of contusions suggests the role of lectin pathway in pathophysiology of brain injury [138].

\section{Present therapeutic strategies of COVID-19}

Many strategies have been directed towards the identification of molecules that can be helpful in the control of COVID-19. The present therapeutic options for COVID-19 include inhibitors of IL- 6 and IL- 1 , anti-TNF- $\alpha$ agents, and colchicine. Corticosteroids, selective cytokine blockade by mAbs (e.g., anakinra or tocilizumab), and Janus kinase (JAK) inhibitors can manage both the cellular entry of CoV-2 and the inflammation. However, in immunological problems, such as cytokine storms, antiviral therapy alone is not effective and needs to be paired with other suitable anti-inflammatory therapies.

\section{Targets of complement inhibitors in COVID-19}

Data have been provided showing that severe COVID-19 is linked to the activation of complement and support for the quest of a therapeutic strategy against complement as a target. Antibodies, recombinant proteins, peptides, small molecules, and siRNA are included in Zelek et al.'s catalog of complement therapies. Eculizumab, a humanized mAb to $\mathrm{C} 5$, is the most common complement inhibitor in clinical practice. It is used in patients with paroxysmal nocturnal hemoglobinuria, atypical hemolytic uremic syndrome, myasthenia gravis, and neuromyelitis optica [139]. These therapies mainly concentrate on adult COVID-19 patients requiring oxygen, such as serious pneumonia, ALI, and ARDS. Clinical trials are in progress to evaluate ravulizumab, vilobelimab (anti-C5a antibody), avdoralimab, and AMY-101. Ravulizumab is being tested against ALI and COVID-19-associated cytokine storms. AIFX-1 mAb is a C5a inhibitor and does not interfere with the role of C5b [140]. Avdoralimab, an inhibitor of solid tumors, is used in patients with COVID-19. COVID-19-associated ARDS is being tested for a new class of C3 inhibitors [105, 141]. RA101295, a C5 complement activation inhibiter, provides survival benefit. It can abolish six sepsis-induced pro-inflammatory cytokines, the expression of IL-6 and IL-8, induced via C5a signaling and lowers coagulopathy [142].

\section{Therapeutic applications of plant lectins in COVID- 19}

\section{Viral glycoproteins as targets for plant lectins}

Plants and natural products are excellent sources of antiviral activity and immune regulation and are being attempted to battle infections induced by resistant microorganisms, including infection with SARC-CoV-2. Lectins are normally identified by their CRDs based on glycan identification, i.e., specificity of CRDs with individual sugars (i.e., mannose, glucose, $\mathrm{N}$-acetylglucosamine, etc.). Increased amounts of affinity for unique high-order sugar structures such as select oligosaccharides can then be introduced by the structural orientation of the human CRD in lectins. Several microbial pathogens, like enveloped viruses, bear glycoproteins on their surface. Carbohydrate moieties of glycoproteins act as mediators for interactions between host cell membrane and the virus fusion and take part in the viral infections. Lectin-dependent therapy, based on protein-carbohydrate interactions, can be used as a substitute to effectively tackle microbial diseases in the future [143-150].

$\mathrm{N}$-glycans present in SARS-CoV spike glycoproteins are high-mannose (Man5-9GlcNAc2) complexes with and without dividing GlcNAc and core fucose [151]. Two targets of possible antiviral intervention in SARS-CoV-2 are as follows: first is the replication cycle of the virus and the second target is located at the end of the infectious virus cycle. High-mannose polymers or mannose-containing glycoproteins are suitable targets for pMBLs. Targeting the structural proteins or cellular receptors of SARS-CoV-2, including S protein and human ACE2, holds promise for the prevention of infection.

Two identified targets for neutralization of SARSCoV-2 are as follows: the virus replication period and the end of the virus infection cycle. But for pMBLs, high-mannose polymers or mannose-containing glycoproteins are acceptable targets. The targeting of SARS-CoV-2 structural proteins or cellular receptors, including $S$ protein and human ACE2, is promising for infection prevention.

\section{Prevention of host-virus interaction by plant MBLs}

In higher plants, mannose-binding lectins are omnipresent, where they act in recognition of 'high-mannose style glycans of foreign microorganisms or plant predators' [19, 143-150]. In addition to their carbohydrate specificity, plant mannosebinding lectins and animal mannose-binding lectins greatly differ in their size, composition, and 3D structures. Many plant lectins like edible garlic (Allium sativum) display a plurality of biological effects including immunomodulations. 
While some garlic immunomodulatory proteins have been identified, their specific characteristics are still unknown [152]. Immunomodulatory activity is known to lead to two main garlic pMBLs, and their features are markedly similar to the plentiful Allium sativum agglutinins I and II [124, 153-158]. It is understood that garlic lectins cause antiinflammatory responses, but much of the study to date has centered on garlic's inhibitory effect on mononuclear cell/ macrophage function. Garlic oil enhanced the lymphocyte proliferation rate accompanied by an elevated production of IL-2, IFN- $\gamma$, IL-4, and IL-10 [159]. Allium sativum lectins have binding affinity to high-mannose oligosaccharide chains. The best manno-oligosaccharide ligand is Man9GlcNAc2Asn, which bears several $\alpha 1$-2-linked mannose residues and needs attention for studies of antiviral activity [160]. Structural studies revealed that the mannose-binding specificity of lectins is mediated by distinct structural scaffolds.

The mannose-specific legume lectins possess the "canonical twelve-stranded $\beta$-sandwich domain ( $\beta$-sandwich structure comprising opposing antiparallel $\beta$-sheets)," while the monocot mannose-binding lectins (such as Galanthus nivalis agglutinin or GNA, and lectins from banana or rice) possess a " $\beta$-prism structure" Jacalin, in addition to galactose, also bind to mannose and mannose-containing glycans. The presence of diversified structural domains in pMBLs, responsible for binding of high mannose-containing glycans, indicates the importance of pMBLs as recognition molecules in higher plants [161-163].

Several plant lectins have been studied in different experimental models of infection $[19,153,157]$. The interaction of plant lectins with immune cells depends on the glycan moieties present on the cell surface. Cell surface interactions are important in signal transduction, which are involved in the response to microbial pathogens $[154,155]$. Plant lectins modulate the production of cytokines and other mediators of the immune response (such as reactive oxygen) and thus improve defenses against microbes $[164,165]$.

\section{Antiviral lectins with specificity for glycan structures}

Several plants, algae, and fungi contain lectins with affinity toward mannose and $\mathrm{N}$-acetylglucosamine (GlcNAc) sugar moieties act potential therapeutic agents for the prevention of viral transmission of HIV, SARS-CoV, and MERS-CoV [146] (Table 1) [164, 166, 167]. Plant lectins for specificity of glycan structures against SARS-CoV have been identified [146]. Among many carbohydrates, mannose-binding lectins (pMBLs) show strongest anti-coronavirus activity. In addition to mannose, some galactose-, $\mathrm{N}$-acetylgalactosamine-, glucose-, and $\mathrm{N}$-acetylglucosamine-specific plant lectins also exhibit anti-coronaviral activity. A positive correlation between the EC50 values of pMBLs against coronaviruses
SARS-CoV, MERS-CoV, and HIV has been suggested [144, 146]. Antiviral plant lectins [144, 146, 149] interfere with viral replication, as in HIV infection, and inhibit viral fusion with target cells. SARS infectivity is diminished by those pMBLs, which are specific for $12 \mathrm{~N}$-glycosylation sites present in the SARS-CoV spike protein [168]. Antiviral lectins with low toxicity offer therapeutic potential and can be included as agents for preventing entry of the virus into cells [144, 149].

\section{Antiviral mannose-binding legume lectins}

The family of legume lectins has been extensively studied. Legume lectins are mainly present in seeds, but smaller quantities are also found in roots, bark, stems, and leaves of plants of legume lectins (Fabaceae genus). Legume lectins play important role in the defense of plants against pests. Similar proteins are present in other plant families and in mammals. A lot of structural information of plant lectins has been derived over the years [144, 145]. Phyto-hemagglutinin (PHA) and Concanavalin A (ConA) or C. ensiformis agglutinin are well-studied members of this lectin family. PHA and ConA are similar in structure characterized by $\beta$-sheets that are connected by $\alpha$ turns, $\beta$ turns, and bends. CRD residues are conserved in most ConA-like lectins. Yet they differ in biological activity and capacity to bind with different ligands [143]. The conserved monosaccharide binding site is present in a variable loop in which four conserved residues from four different regions in protein bestow monosaccharide specificity and a number of subsites around the monosaccharide binding site that harbors additional sugar residues or hydrophobic groups.

A lectin from the seeds of red kidney beans (Phaseolus vulgaris) had a suppressive effect on the growth of fungal species [149]. Monomeric MBL from edible chives (Allium tuberosum) demonstrated mitogenic activity and inhibitory activity in murine splenocytes against human HIV1 reverse transcriptase. HIV1 and HIV2 strains and therapeutic isolates in multiple cell types are selectively blocked by Galanthus nivalis (GNA) and Hippeastrum hybrid (HHA) lectins. These lectins also inhibited infection of $\mathrm{T}$ lymphocytes by different of mutant strains of HIV. GNA and HHA inhibited syncytium formation between infected HIV cells and uninfected T lymphocytes $[149,169,170]$ (Table 1).

The FRIL lectin from hyacinth beans has activity against influenza and anti-SARS-CoV-2. In mice, FRIL is safe against H1N1 viral infection. FRIL is capable of aggregating influenza particles and blocking their nuclear entry as a homotetramer. FRIL also neutralizes SARS-CoV-2 preventing viral protein production in host cells and offers a potential application for the treatment of influenza and COVID-19 [163]. Lectins such as C. ensiformis agglutinin (Con A), Lens culinaris agglutinin (LCA), Vicia faba agglutinin, $P$. 
Table 1 Some important antiviral mannose-binding plant lectins

\begin{tabular}{|c|c|c|c|c|c|c|}
\hline S. no. & Species name & Lectin name & Glycan specificity & $\begin{array}{l}\text { Oligomeric structure } \\
\text { (subunit } \mathrm{MW}, \mathrm{kDa} \text { ) }\end{array}$ & Activity against virus & References \\
\hline 1 & $\begin{array}{l}\text { Artocarpus integri- } \\
\text { folia }\end{array}$ & Jacalin & $\begin{array}{l}\text { Gal } \beta(1,3), \alpha(1,6) \\
\text { GalNAc, Mannose }\end{array}$ & Tetramer (16.5) & HIV & {$[144-147,169]$} \\
\hline 2 & Musa acuminate & BanLec & $\begin{array}{c}\alpha-1,6 \text { mannotetrose } \\
\alpha \text {-D manno/glycosyl, } \\
\alpha-1,3 \text { mannosyl/ } \beta- \\
1,3 \text {-glucosyl }\end{array}$ & Tetramer (15) & $\begin{array}{l}\text { HIV, HCV, H1N1, } \\
\text { H3N2 }\end{array}$ & $\begin{array}{l}{[144-146,162,168,} \\
\quad 170,173]\end{array}$ \\
\hline 3 & Jack-bean (ConA) & ConA & $\begin{array}{l}\alpha \text {-D-mannoside, } \alpha \text {-D- } \\
\text { glucoside }\end{array}$ & Tetramer, (26.5) & HIV, HSV & {$[144-146,170]$} \\
\hline 4 & $\begin{array}{l}\text { Polygonatum Cyr- } \\
\text { tonema Hau }\end{array}$ & PCL & $\alpha(1,3)$ dimannoside & Dimer (12.0) & HIV & [145] \\
\hline 5 & Urtica dioica & UDA & GlcNAc4 & Monomer (8.5) & $\begin{array}{l}\text { HIV, CMV, RSV, } \\
\text { H1N1, SARS-CoV }\end{array}$ & {$[145,168,170]$} \\
\hline 6 & Myrianthus holstii & MHL & GlcNAc, Mannose & Monomer (9.2) & HIV1 & {$[145,170]$} \\
\hline 7 & FRIL dolichos lablab & FRIL & $\begin{array}{l}\text { Trimannosid } \\
\text { Trehalosamine, } \\
\alpha \alpha \text {-trehalose }\end{array}$ & $\begin{array}{l}(\alpha \beta) 2 \text { four } \alpha \text { chains } \\
(14-22 \mathrm{kDa}) \\
\text { and one } \beta \text { chain } \\
(10 \mathrm{kDa})(67)\end{array}$ & HIV1, SARS-CoV-2 & {$[163,172,178]$} \\
\hline 8 & Galanthus nivalis & GNA & $\begin{array}{l}\alpha 1-3 \text { or } \alpha 1-6 \text { linked } \\
\text { mannoses }\end{array}$ & Tetramer (12.4) & $\begin{array}{l}\text { Hepatitis C, Corona } \\
\text { virus }\end{array}$ & $\begin{array}{c}{[144-146,163,} \\
168-170]\end{array}$ \\
\hline 9 & $\begin{array}{l}\text { Hippeastrum hybrid } \\
\text { agglutinin }\end{array}$ & HHA & $\alpha(1,3), \alpha(1,6)-$ & Tetramer (12.5) & $\begin{array}{l}\text { Hepatitis C, Corona- } \\
\text { virus }\end{array}$ & {$[169]$} \\
\hline 10 & Scilla campanulata & SCL & $\begin{array}{l}\alpha(1,3: 1,6)- \\
\quad \text { mannotriose }(\end{array}$ & Tetramer (13.1) & HIV & [145] \\
\hline 11 & Cymbidium hybrid & $\mathrm{CA}$ & Mannose & Dimeric, (12-13) & $\begin{array}{l}\text { HIV1, CMV, RSV, } \\
\text { H1N1 }\end{array}$ & $\begin{array}{l}{[144,145,149,161,} \\
179]\end{array}$ \\
\hline 12 & Epipactis helleborine & EHA & Mannose & Not known & $\begin{array}{l}\text { HIV1, CMV RSV, } \\
\text { H1N1 }\end{array}$ & {$[144,149,161,169]$} \\
\hline 13 & Listera ovata & LOA & Mannose & Dimeric, $(12,5)$ & $\begin{array}{l}\text { HIV1, CMV, RSV, } \\
\text { H1N1 }\end{array}$ & {$[144,149,161,179]$} \\
\hline 14 & Griffithsia sp. & Griffithsin (GRFT) & $\begin{array}{c}\alpha(1,2), \alpha(1,6), \text { man- } \\
\text { notetrose, Man- } 9\end{array}$ & Dimer (12.7) & & {$[145,172,168,169]$} \\
\hline 15 & Cyanovirin-N & $\mathrm{CV}-\mathrm{N}$ & Man-8 and Man-9 & (11) & $\begin{array}{l}\text { HIV1, HIV2, } \\
\text { Ebola,SIV,H1N1, } \\
\text { HSV, measles }\end{array}$ & {$[144-146,170]$} \\
\hline 16 & $\begin{array}{l}\text { Microcystis viridis } \\
\text { lectin }\end{array}$ & MVL & Man6GlcNAc2 & (13) & HIV & [145] \\
\hline 17 & $\begin{array}{l}\text { Oscillatoria agardhii } \\
\text { agglutinin }\end{array}$ & OAA & Man-9 & $(13.9)$ & HIV1, HIV2 & {$[57,163,165]$} \\
\hline 18 & Scytovirin & SVN & $\begin{array}{l}\text { Mannose-oligosac- } \\
\text { charides }\end{array}$ & Monomeric (9.7) & HIV1, Ebola & {$[145,170]$} \\
\hline 19 & Boodlea coacta & BCA & $\alpha 1-2(\operatorname{Man})$ & $13,812 \mathrm{Da}$ & HIV, H1N1 & {$[163,172,178]$} \\
\hline 20 & $\begin{array}{l}\text { Kappaphycus alva- } \\
\text { rezii }\end{array}$ & KAA-2 & $\alpha 1-3$ (Man) & $(30-35)$ & $\mathrm{H} 1 \mathrm{~N} 1$ & $\begin{array}{c}{[144-146,163,} \\
168-170]\end{array}$ \\
\hline
\end{tabular}

$B C o V$ bovine coronavirus, $C M V$ cytomegalovirus, $C o V$ corona virus, $H 1 N 1$ influenza A virus, $H C o V$ human coronavirus, $H C V$ hepatitis $\mathrm{C}$ virus, $H I V$ human immunodeficiency virus, HIVl human immunodeficiency virus $1, H I V 2$ human immunodeficiency virus $2, H S V$-2 herpes simplex virus 2, $I B V$ infectious bronchitis virus, $J E V$ japanese encephalitis virus, $M H V$ mouse hepatitis virus, $P C o V$ puffinosis coronavirus, $R S V$ respiratory syncytial virus, $S A R S-C o V-1$ severe acute respiratory syndrome coronavirus $1, S A R S-C o V$-2 severe acute respiratory syndrome coronavirus 2, SHIV simian-human immunodeficiency virus, SIV simian Immunodeficiency Virus

sativum agglutinin (PSA), and PHA-E bind to the envelope gp120 and inhibit fusion of HIV-infected cells with CD4 cells through a CRD- interaction with HIV-infected cells. Moreover, HIV-1 reverse transcriptase activity is blocked by G.max agglutinins [170,171] and pMBLs from Artocarpus integrifolia (Jacalin), Polygonatum cyrtonema Hau (PCL), Urtica dioica (UDA), and Listera ovata (LOA) have been found to demonstrate antiviral activity (Table 1).

Solomon's Seal (Polygonatum multiflorum), Mistletoe (Viscum album), Iris (Iris hybrid), and Yellow wood 
(Cladastris lutea) are the other plants which possess antiviral lectins against influenza virus. Two members from red algae family have been identified to contain MBP and exhibit antiviral properties against viruses such as herpes, HIV, hepatitis C and Ebola, as well as SARS. These viruses have similar glycoprotein envelopes. The effects of plant-derived pMBLs have been studied in vitro on SARS-CoV and feline infectious peritonitis virus (FIPV). Of the pMBLs tested, 20 antiviral lectins are listed in Table -1 . In addition, some other lectins were antiviral against only SARS, two antiviral against only FIPV, and only eight of the lectins were not antiviral against any of the viruses [168].

\section{Antiviral mannose-binding nonlegume lectins}

Griffithsin (GRFT), cyanovirin-N (CV-N), Microcystis viridis lectin, scytovirin, and banana lectin (BanLec) belong to the group of antiviral nonlegume lectins with encouraging results. Among these, BanLec has been considered as an active antiviral microbicide to prevent infection $[147,166$, 171-175]. An engineered banana pMBL has been shown to retain broad-spectrum activity against multiple influenza strains, including avian strains and largely eliminated harmful mitogenicity of the parent compound [173].

One of the most active viral inhibitors discovered to date is Griffithsin (GRFT), an algae-derived lectin from lower plants. It works as a microbicide against many enveloped viruses with a broad-spectrum function and can inhibit HIV infection at $10^{-12} \mathrm{M}(\mathrm{pM})$ concentrations. Griffithsin's antiviral function is located in its CRD to bind terminal mannoses contained in high-mannose oligosaccharide glycans of the glycoprotein present on the surface of the viral envelope [147]. In order to establish innovative therapies in the field of viral infections, more study is required to investigate algae-related lectins that identify other sugar structures including sialic acid and $\mathrm{N}$-acetyl glucosamine (Table 1).

Two kinds of MBPs are present in the orchidaceae species: Listera ovata and Epipactis helleborine. Seven of these pMBPs possess agglutination activity and exist as dimers of 11-13 kDa subunit each, the eighth MBP is a monomer of $14 \mathrm{kDa}$. A dimeric lectin, isolated from leaves of the twayblade (Listera ovate), is made up of two subunits of $12.5 \mathrm{kDa}$, each having specificity towards mannose and inactivating HIV1, CMV, RSV, and H1N1 [168, 174]. pMBLs from sunflower seedlings show antifungal properties [176]. The mushroom, Agaricus bisporus, pMBL, and the possible occurrence of various other lectins in other species offer therapeutic potential toward cancer cells and a stimulatory effect on the immune system [150].

\section{Conclusions}

According to available scientific information on CoVs infection and the genomic organization of SARS-CoV-2, there are many potential therapeutic targets in humans to develop effective therapies against SARS-CoV-2. The antiviral therapeutics can inhibit the virus replication or stop the entry of the virus into host cells. The main feature of the development of modern therapeutics against infectious diseases is the understanding of host-pathogen interactions. Since sMBL plays an important role in innate immunity, patients may be predisposed to SARS-CoV-2 infection by genetically determined low levels of sMBL. Studies on complement system dysfunction recommend looking for novel therapeutics against complement as a target. Several genetic mutations and SNPs can be a risk factor for cytokine storms in COVID19 arising in a serious disease course and incidence. Prior studies on coronaviruses, mannose-specific plant lectins offer potential applications to prevent SARS-CoV-2 infection in humans.

Since the sMBL plays an important role in innate immunity, genetically determined low levels of sMBL can predispose patients to SARS-CoV-2 infection. Studies on dysfunction of complement system suggest the search of novel therapeutics against complement as target. Several genetic mutations and SNPs may form a risk factor for a severe disease course and the occurrence of cytokine storms in COVID-19. Based on prior studies on coronaviruses, mannose-specific plant lectins offer potential applications to prevent SARS-CoV-2 infection in COVID-19.

Acknowledgements Facilities provided by Panjab University, Chandigarh, to GSG as Professor Emeritus are acknowledged.

Author contributions Concept and writing of MS were performed by GSG, whereas art work and editing were performed by AG.

\section{Declarations}

Conflict of interest Authors declare that they have no matter that could be construed as a potential conflict of interest in this article.

\section{References}

1. Lai CC, Shih TP, Ko WC, Tang HJ, Hsueh PR (2020) Severe acute respiratory syndrome coronavirus 2 (SARS-CoV-2) and Coronavirus disease-2019 (COVID-19). The epidemic and the challenges. Int J Antimicrob Agents. https://doi.org/10.1016/j. ijantimicag.2020.105924

2. Li N, Zhu L, Sun L, Shao G (2021) The effects of novel coronavirus (SARS-CoV-2) infection on cardiovascular diseases and cardiopulmonary injuries. Stem Cell Res 51:102168. https://doi. org/10.1016/j.scr.2021.102168

3. Hasana S, Hossain MF, Jalouli M, Kabir MT, Uddin MG, Wahed MII et al (2021) Genetic diversity of SARS-CoV2 and 
environmental settings: possible association with neurological disorders. Mol Neurobiol 2021:1-15. https://doi.org/10.1007/ s12035-020-02239-Z

4. Li MY, Li L, Zhang Y, Wang XS (2020) Expression of the SARS-CoV-2 cell receptor gene ACE2 in a wide variety of human tissues. Infect Dis Poverty 9:45. https://doi.org/10.1186/ s40249-020-00662-x

5. Shereen MA, Khan S, Kazmi A, Bashir N, Siddique R (2020) COVID-19 infection: origin, transmission, and characteristics of human coronaviruses. J Adv Res 24:91-98. https://doi.org/10. 1016/j.jare.2020.03.005

6. Lu G, Wang Q, Gao GF (2015) Bat-to-human: spike features determining 'host jump' of coronaviruses SARS-CoV, MERS$\mathrm{CoV}$, and beyond. Trends Microbiol 23:468-478. https://doi.org/ 10.1016/j.tim.2015.06.003

7. Wang Q, Zhang Y, Wu L, Niu S, Song C, Zhang Z et al (2020) Structural and functional basis of SARS-CoV-2 entry by using human ACE2. Cell 181:894-904.e9. https://doi.org/10.1016/j. cell.2020.03.045

8. Gkogkou E, Barnasas G, Vougas K, Trougakos IP (2020) Expression profiling meta-analysis of ACE2 and TMPRSS2, the putative anti-inflammatory receptor and priming protease of SARSCoV-2 in human cells, and identification of putative modulators. Redox Biol 36(2020):101615. https://doi.org/10.1016/j.redox. 2020.101615

9. Hoffmann M, Kleine-Weber H, Schroeder S, Krüger N et al (2020) SARS-CoV-2 Cell entry depends on ACE2 and TMPRSS 2 and is blocked by a clinically proven protease inhibitor. Cell 181(271-280):e8. https://doi.org/10.1016/j.cell.2020.02. 052

10. Letko M, Marzi A, Munster V (2020) Functional assessment of cell entry and receptor usage for SARS-CoV-2 and other lineage B betacoronaviruses. Nat Microbiol 5:562-569. https://doi.org/ 10.1038/s41564-020-0688-y

11. Shajahan A, Supekar NT, Gleinich AS, Azadi P (2020) Deducing the $\mathrm{N}$ - and $\mathrm{O} 284$ glycosylation profile of the spike protein of novel coronavirus SARS-CoV-2. Glycobiology. https://doi.org/ 10.1093/glycob/cwaa042

12. Watanabe Y, Allen JD, Wrapp D, McLellan JS, Crispin M (2020) Site-specific glycan analysis of the SARS-CoV-2 spike. Science 369:330-333. https://doi.org/10.1126/science.abb9983

13. Amraie R, Napoleon MA, Yin W, Berrigan J, Suder E, Zhao G et al (2020) CD209L/L-SIGN and CD209/DC-SIGN act as receptors for SARS-CoV-2 and are differentially expressed in lung and kidney epithelial and endothelial cells. Version 1. bioRxiv. https://doi.org/10.1101/2020.06.22.165803

14. van Kooyk Y, Rabinovich GA (2008) Protein-glycan interactions in the control of innate and adaptive immune responses. Nat Immunol 9:593-601. https://doi.org/10.1038/ni.f.203

15. Gupta GS (2012) Animal lectins: form function and clinical applications. Springer, Wien

16. Gao Y-L, Du Y, Zhang C, Cheng C, Yang H-Y, Jin Y-F et al (2020) Role of renin-angiotensin system in acute lung injury caused by viral infection. Infect Drug Resist 13:3715-3725. https://doi.org/10.2147/IDR.S265718

17. Dam TK, Brewer CF (2010) Lectins as pattern recognition molecules: the effects of epitope density in innate immunity. Glycobiology 20:270-279. https://doi.org/10.1093/glycob/cwp186

18. Gupta GS (2012) Lectins: an overview. In: Gupta GS (ed) Animal lectins: form function and clinical applications. Springer, Wien, pp 3-25

19. Ribeiro AC, Ferreira R, Rreitas R (2018) Plant Lectins: Bioactivities and Bioapplications. In: Atta-ur-Rahman (eds) Studies in Natural Products Chemistry. Elsevier, Amsterdam

20. Xu Z, Shi L, Wang Y, Zhang J, Huang L et al (2020) Pathological findings of COVID-19 associated with acute respiratory distress syndrome. Lancet Respir Med 8:420-422. https://doi.org/10. 1016/S2213-2600(20)30076-X

21. Trougakos IP, Stamatelopoulos K, Terpos E, Tsitsilonis OE, Aivalioti E, Paraskevis D et al (2021) Insights to SARS-CoV-2 life cycle, pathophysiology, and rationalized treatments that target COVID-19 clinical complications. J Biomed Sci 28:9. https:// doi.org/10.1186/s12929-020-00703-5

22. Donoghue M, Hsieh F, Baronas E, Godbout K, Gosselin M et al (2000) A novel angiotensin-converting enzyme-related carboxypeptidase (ACE2) converts angiotensin I to angiotensin 1-9. Circ Res 87:e1-e9. https://doi.org/10.1161/01.RES.87.5.e1

23. Zhou P, Yang XL, Wang XG, Hu B, Zhang L, Zhang W et al (2020) A pneumonia outbreak associated with a new coronavirus of probable bat origin. Nature 579:270-273. https://doi.org/10. 1038/s41586-020-2012-7

24. Chen Y, Shan K, Qian W (2020) Asians and other races express similar levels of and share the same genetic polymorphisms of the SARS-CoV-2 cell-entry receptor. https://doi.org/10.20944/ preprints202002.0258.v1

25. Wang PH, Cheng Y (2020) Increasing host cellular receptor-angiotensin-converting enzyme 2 (ACE2) expression by coronavirus may facilitate 2019-nCoV infection. bioRxiv. https://doi.org/10. 1101/2020.02.24.963348

26. Ni W, Yang X, Yang D, Bao J, Li R, Xiao Y et al (2020) Role of angiotensin-converting enzyme 2 (ACE2) in COVID-19. Crit Care 24:422. https://doi.org/10.1186/s13054-020-03120-0

27. Wang C, Wang S, Li D, Zhao X, Han S, Wang T (2020) Lectinlike intestinal defensin inhibits 2019-nCoV spike binding to ACE2. Biorxiv. https://doi.org/10.1101/2020.03.29.013490

28. Actor JK (2012) Mononuclear cells and macrophages. In: Elsevier's integrated review immunology and microbiology (e book).

29. Biron CA (2016) Viral pathogenesis

30. Jack DL, Turner MW (2003) Anti-microbial activities of mannose-binding lectin. Biochem Soc Trans 31(Pt 4):753-757. https://doi.org/10.1042/bst0310753

31. Lucar O, Reeves RK, Jost S (2019) A natural impact: NK cells at the intersection of cancer and HIV disease. Front Immunol. https://doi.org/10.3389/fimmu.2019.01850

32. Masselli E, Vaccarezza M, Carubbi C, Pozzi G, Presta V et al (2020) NK cells: a double edge sword against SARS-CoV-2. Adv Biol Regul 77:100737. https://doi.org/10.1016/j.jbior.2020. 100737

33. Vacca P, Munari E, Tumino N, Moretta F, Pietra G et al (2018) Human natural killer cells and other innate lymphoid cells in cancer: friends or foes? Immunol Lett 201:14-19. https://doi. org/10.1016/j.imlet.2018.11.004

34. Zhang C, Wang XM, Li SR, Twelkmeyer T, Wang WH, Zhang SY et al (2019) NKG2A is an NK cell exhaustion checkpoint for HCV persistence. Nat Commun 10:1507. https://doi.org/10.1038/ s41467-019-09212-y

35. Gupta A (2012) Collectins: mannan-binding protein as a model lectin. In: Gupta GS (ed) Animal lectins: form, function and clinical applications. Springer, Wien, pp 483-499

36. Gupta A (2012) MBL deficiency as risk of infection and autoimmunity. In: Gupta GS (ed) Animal lectins: form, function and clinical applications. Springer, Wien, pp 933-953

37. Monticielo OA, Mucenic T, Xavier RM, Brenol JC, Chies JA (2008) The role of mannose-binding lectin in systemic lupus erythematosus. Clin Rheumatol 27:413-419. https://doi.org/10. 1007/s10067-008-0838-8

38. Pradhan V, Surve P, Ghosh, (2010) Mannose binding lectin (MBL) in autoimmunity and its role in systemic lupus erythematosus (SLE). J Assoc Phys India 58:688-690

39. Gupta A, Gupta GS (2012) C-type lectins family. In: Gupta GS (ed) Animal lectins: form function and clinical applications. Springer, Wien, pp 473-482 
40. Weis WI, Taylor ME, Drickamer K (1998) The C-type lectin superfamily in the immune system. Immunol Rev 163:19-34. https://doi.org/10.1111/j.1600-065x.1998.tb01185.x

41. Sheriff S, Chang CY, Ezekowitz RA (1994) Human mannosebinding protein carbohydrate recognition domain trimerizes through a triple alpha-helical coiled-coil. Nat Struct Biol 1:789794. https://doi.org/10.1038/nsb1194-789

42. Weis WI, Kahn R, Fourme R, Hendrickson DK (1991) Structure of the calcium-dependent lectin domain from a rat mannosebinding protein determined by MAD phasing. Science 254:608615. https://doi.org/10.1126/science.1721241

43. Kase T, Suzuk Y, Kawai T, Sakamoto T, Ohtani K, Eda S et al (1999) Human mannan-binding lectin inhibits the infection of influenza A virus without complement. Immunology 97:385392. https://doi.org/10.1046/j.1365-2567.1999.00781.x

44. Liu XH, Li Q, Zhang P, Su Y, Zhang XR, Sun Q (2014) Serum mannose-binding lectin and $\mathrm{C}$-reactive protein are potential biomarkers for patients with community-acquired pneumonia. Genet Test Mol Biomarkers 18:630-635. https://doi.org/10.1089/gtmb. 2014.0038

45. Swale A, Miyajima F, Kolamunnage-Dona R, Roberts P, Little M, Beeching NJ et al (2014) Serum mannose-binding lectin concentration, but not genotype, is associated with clostridium difficile infection recurrence: a prospective cohort study. Clin Infect Dis 59:1429-1436. https://doi.org/10.1093/cid/ciu666

46. Justice JM, Sleasman JW, Lanza DC (2015) recalcitrant rhinosinusitis, innate immunity and mannose-binding lectin. Ann Otol Rhinol Laryngol 124:102-106. https://doi.org/10.1177/00034 89414543680

47. Gao DN, Zhang Y, Ren YB, Kang J, Jiang L, Feng Z et al (2015) relationship of serum mannose-binding lectin levels with the development of sepsis: a meta-analysis. Inflammation 38:338347. https://doi.org/10.1007/s10753-014-0037-517

48. Luo J, Xu F, Lu GJ, Lin HC, Feng ZC (2014) Low mannosebinding lectin (MBL) levels and MBL genetic polymorphisms associated with the risk of neonatal sepsis: An updated metaanalysis. Early Hum Dev 90:557-564. https://doi.org/10.1016/j. earlhumdev.2014.07.007

49. Zogheib E, Nyga R, Cornu M, Sendid B, Jounieaux V et al (2018) Prospective observational study on the association between serum mannose-binding lectin levels and severe outcome in critically ill patients with pandemic influenza Type A (H1N1) infection. Lung 196:65-72. https://doi.org/10.1007/ s00408-017-0067-5

50. Ling MT, Tu W, Han Y, Mao H, Chong WP, Guan J et al (2012) Mannose-binding lectin contributes to deleterious inflammatory response in pandemic h1n1 and avian $\mathrm{h} 9 \mathrm{n} 2$ infection. J Infect Dis 205:44-53. https://doi.org/10.1093/infdis/jir691

51. Song GG, Bae SC, Seo YH, Kim JH, Choi SJ, Ji JD, Lee YH (2014) Meta-analysis of functional MBL polymorphisms. Associations with rheumatoid arthritis and primary Sjögren's syndrome. Z Rheumatol 73:657-664. https://doi.org/10.1007/ s00393-014-1408-X

52. Gravina LP, Crespo C, Giugno H, Sen L, Chertkoff L, Mangano A, Castaños C (2015) Mannose-binding lectin gene modifier of cystic fibrosis phenotype in Argentinean pediatric patients. J Cyst Fibros 14:78-83. https://doi.org/10.1016/j.jcf.2014.07. 012

53. Dong L, Wu J, Chen K, Xie J, Wang Y, Li D, Liu Y, Yin A et al (2019) Mannan-binding lectin attenuates inflammatory arthritis through the suppression of osteoclastogenesis. Front Immunol 10:1239. https://doi.org/10.3389/fimmu.2019.01239

54. Gupta A, Gupta RK, Gupta GS (2009) Targeting cells for drug and gene delivery: emerging applications of mannans and mannan binding lectins. J Sci Ind Res 68:465-483
55. Noris M, Benigni A, Remuzzi G (2020) The case of complement activation in COVID-19 multiorgan impact. Kidney Int 98:314-322. https://doi.org/10.1016/j.kint.2020.05.013

56. Auriti C, Prencipe G, Caravale B, Coletti MF, Ronchetti MP, Piersigilli $F$ et al (2014) MBL2 gene polymorphisms increase the risk of adverse neurological outcome in preterm infants: a preliminary prospective study. Pediatr Res 76:464-469. https:// doi.org/10.1038/pr.2014.118

57. Bouwman LH, Eerligh P, Terpstra OT, Daha MR, de Knijff $P$, Ballieux BEPB et al (2005) Elevated levels of mannose-binding lectin at clinical manifestation of type 1 diabetes in juveniles. Diabetes 54:3002-3006. https://doi.org/10.2337/diabetes.54.10. 3002

58. Tran HB, Ahern J, Hodge G, Holt P, Dean MM, Reynolds PN, Hodge $S$ (2014) Oxidative stress decreases functional airway mannose binding lectin in COPD. PLoS ONE 9:e98571. https:// doi.org/10.1371/journal.pone.0098571

59. Hornum M, Bay JT, Clausen P, Hansen JM, Mathiesen ER et al (2014) High levels of mannose-binding lectin are associated with lower pulse wave velocity in uraemic patients. BMC Nephrol 15:162. https://doi.org/10.1186/1471-2369-15-162

60. Nonaka M, Imaeda H, Matsumoto S, Yong Ma B, Kawasaki N, Mekata E et al (2014) Mannan-binding protein, a C-type serum lectin, recognizes primary colorectal carcinomas through tumorassociated Lewis glycans. J Immunol 192:1294-1301. https://doi. org/10.4049/jimmunol.1203023

61. Chen M, Deng J, Su C, Li J, Wang M, Abuaku BK et al (2014) Impact of passive smoking, cooking with solid fuel exposure, and MBL/MASP-2 gene polymorphism upon susceptibility to tuberculosis. Int J Infect Dis 29:1-6. https://doi.org/10.1016/j. ijid.2014.08.010

62. Ip WK, Chan KH, Law HK, Tso GH, Kong EK, Wong WH et al (2005) Mannose-binding lectin in severe acute respiratory syndrome coronavirus infection. J Infect Dis 191:1697-1704. https:// doi.org/10.1086/429631

63. Zhang H, Zhou G, Zhi L, Yang H, Zhai Y, Dong X, Zhang X, Gao X, Zhu Y, He F (2005) Association between mannosebinding lectin gene polymorphisms and susceptibility to severe acute respiratory syndrome coronavirus infection. J Infect Dis 192:1355-1361. https://doi.org/10.1086/491479

64. Yuan FF, Tanner J, Chan PKS, Biffin S, Dyer WB, Geczy AF et al (2005) Influence of Fc $\gamma$ RIIA and MBL polymorphisms on severe acute respiratory syndrome. Tissue Antigens 66:291-296. https://doi.org/10.1111/j.1399-0039.2005.00476

65. Li H, Tang NL, Chan PKS, Wang CY, Hui DSC, Luk C, Kwok $\mathrm{R}$ (2008) Polymorphisms in the C-type lectin genes cluster in chromosome 19 and predisposition to severe acute respiratory syndrome coronavirus (SARS-CoV) infection. J Med Genet 45:752-758. https://doi.org/10.1136/jmg.2008.058966

66. Tu X, Chong WP, Zhai Y, Zhang H, Zhang F, Wang S, Liu W, Wei M, Siu NH, Yang H et al (2015) Functional polymorphisms of the CCL2 and MBL genes cumulatively increase susceptibility to severe acute respiratory syndrome coronavirus infection. J Infect 71:101-109. https://doi.org/10.1016/j.jinf.2015.03.006

67. Nedovic B, Posteraro B, Leoncini E, Ruggeri A, Amore R et al (2014) Mannose-binding lectin codon 54 gene polymorphism and vulvovaginal candidiasis: a systematic review and metaanalysis. Biomed Res Int 2014:738298. https://doi.org/10.1155/ 2014/738298

68. Garred P, Genster N, Pilely K, Bayarri-Olmos R, Rosbjerg A, Ma YJ, Skjoedt MO (2016) A journey through the lectin pathway of complement-MBL and beyond. Immunol Rev 274:74-97. https:// doi.org/10.1111/imr. 12468

69. Madsen HO, Garred P, Kurtzhals JA, Lamm LU, Ryder LP, Thiel $S$ et al (1994) A new frequent allele is the missing link in the 
structural polymorphism of the human mannan-binding protein. Immunogenetics 40:37-44. https://doi.org/10.1007/BF00163962

70. Madsen HO, Satz ML, Hogh B, Svejgaard A, Garred P (1998) Different molecular events result in low protein levels of mannanbinding lectin in populations from southeast Africa and South America. J Immunol 161:3169-3175

71. McKechnie JL, Blish CA (2020) The innate immune system: fighting on the front lines or fanning the flames of COVID-19? Cell Hosts Microb 27:863-869

72. Thiel S, Frederiksen PD, Jensenius JC (2006) Clinical manifestations of mannan-binding lectin deficiency. Mol Immunol 43:86-96. https://doi.org/10.1016/j.molimm.2005.06.018

73. Gupta A, Gupta RK (2012) Pulmonary SP-A: forms and functions. In: Gupta GS (ed) Animal lectins: form function and clinical applications. Springer, Wien, pp 501-525

74. Sastry K, Herman GA, Day L, Deignan E, Bruns G, Morton CC et al (1989) The human mannose-binding protein gene. Exon structure reveals its evolutionary relationship to a human pulmonary surfactant gene and localization to chromosome 10. J Exp Med 170:1175-1189. https://doi.org/10.1084/jem.170.4.1175

75. Gupta A, Gupta RK (2012) Pulmonary SP-D: forms and functions. In: Gupta GS (ed) Animal lectins: form function and clinical applications. Springer, Wien, pp 527-550

76. Lee SG, Yum JS, Moon HM, Kim HJ, Yang YJ, Kim HL et al (2005) Analysis of mannose-binding lectin 2 (MBL2) genotype and the serum protein levels in the Korean population. Mol Immunol 42:969-977. https://doi.org/10.1016/j.molimm.2004. 09.036

77. Kiseljaković E, Hasić S, Valjevac A, Mačkić-Đurović M, Jadrić $\mathrm{R}$, Mehić B et al (2014) Association of mannose-binding lectin 2 (MBL2) gene heterogeneity and its serum concentration with osteoporosis in postmenopausal women. Bosn J Basic Med Sci 14:25-29. https://doi.org/10.17305/bjbms.2014.2292

78. Wang F, Li Y, Yang C, Mu Y, Wang Y, Zhang W et al (2019) Mannan-binding lectin suppresses peptidoglycan-induced tlr2 activation and inflammatory responses. Mediat Inflamm 2019:1349784. https://doi.org/10.1155/2019/1349784

79. Zhao N, Wu J, Xiong S, Zhang L, Lu X, Chen S, Qifeng Wu et al (2017) Mannan-binding lectin, a serum collectin, suppresses T-cell proliferation via direct interaction with cell surface calreticulin and inhibition of proximal T-cell receptor signaling. FASEB J 31:2405-2417. https://doi.org/10.1096/fj.20160 1200RR

80. Wang M, Zhang Y, Chen Y, Chen Z (2011) Mannan-binding lectin regulates dendritic cell maturation and cytokine production induced by lipopolysaccharide. BMC Immunol 12:1. https://doi. org/10.1186/1471-2172-12-1

81. Scoville SD, Freud AG, Caligiuri MA (2017) Modeling human natural killer cell 674 development in the era of innate lymphoid cells. Front Immunol 8:360. https://doi.org/10.3389/fimmu.2017. 00360

82. Mirandola P, Gobbi G, Sponzilli I, Pambianco M, Malinverno $\mathrm{C}$ et al (2007) Exogenous hydrogen sulfide induces functional inhibition and cell death of cytotoxic lymphocytes subsets. J Cell Physiol 213:826-833. https://doi.org/10.1002/jcp.21151

83. Vitale M, Matteucci A, Manzoli L, Rodella L, Mariani AR, Zauli G et al (2001) Interleukin 2 activates nuclear phospholipase Cbeta by mitogen-activated protein kinase-dependent phosphorylation in human natural killer cells. FASEB J 15:1789-1791. https://doi.org/10.1096/fj.01-0008fje

84. Zheng M, Gao Y, Wang G, Song G, Liu S, Sun D, Xu Y, Tian $\mathrm{Z}$ (2020) Functional exhaustion of antiviral lymphocytes in COVID-19 patients. Cell Mol Immunol 17:533-535. https:// doi.org/10.1038/s41423-020-0402-2

85. Antonioli L, Fornai M, Pellegrini C, Blandizzi C (2020) NKG2A and COVID-19: another brick in the wall. Cell
Mol Immunol 17:672-674. https://doi.org/10.1038/ s41423-020-0450-7

86. Wilk A, Rustagi A, Zhao NQ, Roque J, Martinez-Colon GJ, McKechnie JL et al (2020) A single-cell atlas of the peripheral immune response to severe COVID-19. Nat Med 26:1070-1076. https://doi.org/10.1038/s41591-020-0944-y

87. Xiong Y, Liu Y, Cao L, Wang D, Guo M, Jiang A et al (2020) Transcriptomic characteristics of bronchoalveolar lavage fluid and peripheral blood mononuclear cells in COVID-19 patients. Emerg Microb Infect 9:761-770. https://doi.org/10.1080/22221 751.2020 .1747363

88. Sinha P, Matthay MA, MA, Calfee CS, (2020) Is a "cytokine storm" relevant to COVID-19? JAMA Intern Med 180(9):11521154. https://doi.org/10.1001/jamainternmed.2020.3313

89. Mao H, Tu HW, Qin G, Law HK, Sia SF, Chan PL (2009) Influenza virus directly infects human natural killer cells and induces cell apoptosis. J Virol 83:9215-9222. https://doi.org/10.1128/ JVI.00805-09

90. Travaglini KJ, Nabhan AN, Penland L, Sinha R, Gillich A, Sit $\mathrm{RV}$, Chang $\mathrm{S}$ et al (2020) A molecular cell atlas of the human lung from single cell RNA sequencing. bioRxiv 27:1-76

91. Ramsuran V, Naranbhai V, Horowitz A, Qi Y, Martin MP, Yuki $Y$ et al (2018) Elevated HLA-A expression impairs HIV control through inhibition of NKG2A-expressing cells. Science 359:8690. https://doi.org/10.1126/science.aam8825

92. Diao B, Wang C, Tan Y, Chen X, Liu Y, Ning L et al (2020) Reduction and functional exhaustion of T cells in patients with coronavirus disease 2019 (COVID-19). Front Immunol. https:// doi.org/10.3389/fimmu.2020.00827

93. Zhou J, Mengyao H, Jie L, Liu Y, Luo J, Zhang L, Lu X, Zuo D, Chen Z (2019) Mannan-binding lectin regulates inflammatory cytokine production, proliferation, and cytotoxicity of human peripheral natural killer cells. Mediators Inflamm. https://doi. org/10.1155/2019/6738286

94. Zhou J, Li J, Yu Y, Liu Y, Li H et al (2019) Mannan-binding lectin deficiency exacerbates sterile liver injury in mice through enhancing hepatic neutrophil recruitment. J Leukoc Biol 105:177-186. https://doi.org/10.1002/JLB.3A0718-251R

95. Khadke S, Ahmed N, Ahmed N, Ratts R, Raju S, Gallogly M, et al (2020) Virol J 17:154

96. Cron R, Behrens EM (2019) In: Cron R, Behrens EM (eds) Cytokine storm syndrome. Springer, New York

97. Tang Y, Liu J, Zhang D, Xu Z, Ji J, Wen C (2020) Cytokine storm in COVID-19: the current evidence and treatment strategies. Front Immunol 11:1708. https://doi.org/10.3389/fimmu. 2020.01708

98. Mangalmurti N, Hunter CA (2020) Cytokine storms: understanding COVID-19. Immunity 53:19-25. https://doi.org/10.1016/j. immuni.2020.06.017

99. Li X, Geng M, Peng Y, Meng L, Lu S (2020) Molecular immune pathogenesis and diagnosis of COVID-19. J Pharm Anal 10:102108. https://doi.org/10.1016/j.jpha.2020.03.001

100. Xu D, Zhang H, Gong H, Chen J, Ye J, Meng T et al (2020) Identification of a potential mechanism of acute kidney injury during the Covid-19 outbreak: a study based on single-cell transcriptome analysis. Intensive Care Med 46:1114-1116. https:// doi.org/10.1007/s00134-020-06026-1

101. Barnes BJ, Adrover JM, Baxter-Stoltzfus A, Borczuk A, CoolsLartigue J et al (2020) Targeting potential drivers of COVID-19: Neutrophil extracellular trap. J Exp Med 217:e20200652. https:// doi.org/10.1084/jem.20200652

102. Mehta P, McAuley DF, Brown M, Sanchez E, Tattersall RS, Manson JJ (2020) HLH across speciality collaboration, UKCOVID-19: consider cytokine storm syndromes and immunosuppression. Lancet 395:1033-1034. https://doi.org/10.1016/ S0140-6736(20)30628-0 
103. Kox M, Waalders NJB, Kooistra EJ et al (2020) Cytokine levels in critically ill patients with COVID-19 and other onditions. JAMA 324:1565-1567. https://doi.org/10.1001/jama.2020.17052

104. Liu T, Zhang J, Yang Y, Ma H, Li Z, Zhang J et al (2020) The potential role of IL-6 in monitoring coronavirus disease 2019. medRxiv. https://doi.org/10.2139/ssrn.3548761

105. Chen X, Zhao B, Qu Y, Chen Y, Xiong J, Feng Y et al (2020) Detectable serum SARS-CoV-2 viral load (RNAaemia) is closely correlated with drastically elevated interleukin 6 (IL-6) level in critically ill COVID-19 patients. Clin Infect Dis. https://doi.org/ 10.1093/cid/ciaa449

106. Zhang C, Wu Z, Li JW, Zhao H, Wang GQ (2020) Cytokine release syndrome in severe COVID-19: interleukin-6 receptor antagonist tocilizumab may be the key to reduce mortality. Int J Antimicrob Agents 55:105954. https://doi.org/10.1016/j.ijant imicag.2020.105954

107. Elvington M, Liszewski MK, Atkinson JP (2016) Evolution of the complement system: from defense of the single cell to guardian of the intravascular space. Immunol Rev 274:9-15. https:// doi.org/10.1111/imr.12474

108. Bain W, Li H, van der Geest R, Moore SR, Olonisakin TF, Ahn $B$ et al (2020) Increased alternative complement pathway function and improved survival during critical illness. Am J Respir Crit Care Med 202:230-240. https://doi.org/10.1164/rccm. 201910-2083OC

109. Java A, Apicelli AJ, Liszewski MK, Coler-Reilly A, Atkinson JP, Kim AHJ, Kulkarni HS (2020) The complement system in COVID-19: friend and foe? JCI Insight 5:e140711. https://doi. org/10.1172/jci.insight. 140711

110. Xiao W, Li G, Shen B (2019) The role of C5a in acute lung injury induced by highly pathogenic viral infections. Emerg Microb Infect. https://doi.org/10.1038/emi.2015.28

111. Luo S, Hu D, Wang M, Zipfel PF, Hu Y (2020) Complement in hemolysis- and thrombosis- related diseases. Front Immunol 11:1212. https://doi.org/10.3389/fimmu.2020.01212

112. Zhao X, Chen YX, Li CS (2015) Predictive value of the complement system for sepsis-induced disseminated intravascular coagulation in septic patients in emergency department. J Crit Care 30:290-295. https://doi.org/10.1016/j.jcrc.2014.11.007

113. Risitano AM, Mastellos DC, Huber-Lang M, Yancopoulou D, Garlanda C, Ciceri F et al (2020) Complement as a target in COVID-19? Nat Rev Immunol 20:448. https://doi.org/10.1038/ s41577-020-0366-6

114. Ramlall V, Thangaraj P, Meydan C, Foox J, Butler D, May B et al (2020) (2020) Identification of immune complement function as a determinant of adverse SARS-CoV-2 infection outcome. Preprint medRxiv 05(05):20092452. https://doi.org/10.1101/2020. 05.05.20092452

115. Kulasekararaj AG, Lazana I, Large J, Posadas K, Eagleton H, Villajin JL et al (2020) Terminal complement inhibition dampens the inflammation during COVID-19. Br J Haematol 190:e141e143. https://doi.org/10.1111/bjh.16916

116. Noris M, Remuzzi G (2013) Overview of complement activation and regulation. Semin Nephrol 33:479-492. https://doi.org/10. 1016/j.semnephrol.2013.08.001

117. Gao T, Hu M, Zhang X, Li H, Zhu L, Liu H, Dong Q et al (2020) Highly pathogenic coronavirus $\mathrm{N}$ protein aggravates lung injury by MASP-2-mediated complement over-activation. medRxiv. https://doi.org/10.1101/2020032920041962v2

118. Magro C, Mulvey JJ, Berlin D, Nuovo G, Salvatore S, Harp J et al (2020) Complement associated microvascular injury and thrombosis in thepathogenesis of severe COVID-19 infection: a report of five cases. Transl Res 220:113. https://doi.org/10. 1016/j.trs1.2020.04.007-0

119. Henry BM, Vikse J, Benoit S, Favaloro EJ, Lippi L (2020) Hyper-inflammation and Derangement of
Renin-Angiotensin-aldosterone system in COVID-19: a novel hypothesis for clinically suspected hypercoagulopathy and microvascular immunothrombosis. Clin Chim Acta 507:167173. https://doi.org/10.1016/j.cca.2020.04.027

120. Zhang B, Zhou X, Zhu C, Feng F, Qiu Y, Feng J et al (2020) Immune phenotyping based on neutrophil-to-lymphocyte ratio and $\mathrm{IgG}$ predicts disease severity and outcome for patients with COVID-19. medRxiv. https://doi.org/10.1101/2020.03. 12.20035048

121. Walls AC, Park YJ, Tortorici MA, Wall A, McGuire AT, Veesler D (2020) Structure, function, and antigenicity of the SARS-CoV-2 spike glycoprotein. Cell 181:281-292.e6. https:// doi.org/10.1016/j.cell.2020.02.058

122. Polycarpou A, Howard M, Farrar CA, Greenlaw R, Fanelli G, Wallis R, Klavinskis LS et al (2020) Rationale for targeting complement in COVID-19. EMBO Mol Med 12:12642

123. Semis M, Gugiu GB, Bernstein EA, Bernstein KE, Kalkum M (2019) The plethora of angiotensin-converting enzyme-processed peptides in mouse plasma. Anal Chem 91:6440-6453. https://doi.org/10.1021/acs.analchem.8b03828

124. Jiang Y, Zhao G, Song N, Li P, Chen Y, Guo Y et al (2018) Blockade of the C5a-C5aR axis alleviates lung damage in hDPP4-transgenic mice infected with MERS-CoV. Emerg Microbes Infect 7:77. https://doi.org/10.1038/ s41426-018-0063-8

125. Shen B, Yi X, Yaoting S, Tiannan G et al (2020) Proteomic and metabolomic characterization of COVID-19 patient sera. Cell 2020(182):59-72. https://doi.org/10.1016/j.cell.2020.05.032

126. Li Y, Wang Y, Liu H, Sun W, Ding B, Zhao Y et al (2020) Urine proteome of COVID-19 patients. medRxiv. https://doi.org/10. 1101/2020.05.02.20088666

127. Gralinski LE, Sheahan TP, Morrison TE, Menachery VD, Jensen $\mathrm{K}$, Leist SR et al (2018) Complement activation contributes to severe acute respiratory syndrome coronavirus pathogenesis. mBio 9:e01753-e1818. https://doi.org/10.1128/mBio.01753-18

128. Sun S, Zhao G, Liu C, Fan W, Zhou X, Lin Zeng L et al (2015) Treatment with anti-C5a antibody improves the outcome of $\mathrm{H} 7 \mathrm{~N} 9$ virus infection in african green monkeys. Clin Infect Dis 60:586-595. https://doi.org/10.1093/cid/ciu887

129. Garred P, Madsen HO, Balslev U, Hofmann B, Pedersen C, Gerstoft J et al (1997) Susceptibility to HIV infection and progression of AIDS in relation to variant alleles of mannose-binding lectin. Lancet 349:236-240. https://doi.org/10.1016/S01406736(96)08440-1

130. Koch A, Melbye M, Sorensen P, Homoe P, Madsen HO, Molbak $\mathrm{K}$ et al (2001) Acute respiratory tract infections and mannosebinding lectin insufficiency during early childhood. JAMA 285:1316-1321. https://doi.org/10.1001/jama.285.10.1316

131. Hibberd ML, Sumiya M, Summerfield JA, Booy R, Levin M (1999) Association of variants of the gene for mannose-binding lectin with susceptibility to meningococcal disease Meningococcal Research Group. Lancet 353:1049-1053. https://doi.org/10. 1016/S0140-6736(98)08350-0

132. Wei XS, Wang XR, Zhang JC, Yang WB, Ma WL, Yang BH et al (2020) A cluster of health care workers with COVID19 pneumonia caused by SARS-CoV-2. J Microbiol Immunol Infect. https://doi.org/10.1016/j.jmii.2020.04.013

133. Gupta GS (2012) Pentraxins: the L-type lectins and the C-reactive protein as a cardiovascular risk. In: Gupta GS (ed) Animal lectins: form function and clinical applications. Springer, Wien, pp 163-188

134. Fidler KJ, Wilson P, Davies JC, Turner MW, Peters MJ, Klein NJ (2004) Increased incidence and severity of the systemic inflammatory response syndrome in patients deficient in mannose-binding lectin. Intensive Care Med 30:1438-1445. https:// doi.org/10.1007/s00134-004-2303-8 
135. Smole U, Kratzer B, Pickl WF (2020) Soluble pattern recognition molecules: guardians and regulators of homeostasis at airway mucosal surfaces. Eur J Immunol 50:624-642. https:// doi.org/10.1002/eji.201847811

136. Casals C, Campanero-Rhodes MA, García-Fojeda B, Solís D (2018) The role of collectins and galectins in lung innate immune defense. Front Immunol 9:1998. https://doi.org/10. 3389/fimmu.2018.01998

137. Vengenet IT, Enger TB, Videm V, Garred P (2017) Pentraxin, ficolin-2 and lectin pathway associated serine protease MASP-3 as early predictors of myocardial infarction - the HUNT2 study. Sci Rep 7:43045. https://doi.org/10.1038/srep4 3045

138. de Blasio DD, Fumagalli S, Orsini P, Neglia L, Perego C et al (2019) Human brain trauma severity is associated with lectin complement pathway activation. J Cereb Blood Flow Metab 39:794-807. https://doi.org/10.1177/0271678X18758881

139. Zelek WM, Xie L, Morgan BP, Harris CL (2019) Compendium of current complement therapeutics. Mol Immunol 114:341-352. https://doi.org/10.1016/j.molimm.2019.07.030

140. Riedemann NC, Habel M, Ziereisen J, Hermann M, Schneider C, Cyrill Wehling C et al (2017) Controlling the anaphylatoxin $\mathrm{C} 5 \mathrm{a}$ in diseases requires a specifically targeted inhibition. Clin Immunol 180:25-32. https://doi.org/10.1016/j.clim.2017.03.012

141. Mastaglio S, Ruggeri A, Risitano AM, Angelillo P, Yancopoulou D, Mastellos DC et al (2020) The first case of COVID-19 treated with the complement C3 inhibitor AMY-101. Clin Immunol 215:108450. https://doi.org/10.1016/j.clim.2020.108450

142. Keshari RS, Silasi-Mansat R, Popescu NI, Langer M, Chaaban $\mathrm{H}$, Lupu $\mathrm{C}$ et al (2015) Complement C5 inhibition blocks the cytokine storm and consumptive coagulopathy by decreasing lipopolysaccharide (LPS) release in E. coli sepsis. Blood 126:765. https://doi.org/10.1182/blood.V126.23.765.765

143. Cavada BS, Pinto-Junior VR, Osterne VJS, Nascimento KS (2019) ConA-like lectins: high similarity proteins as models to study structure/biological activities relationships. Int J Mol Sci 20:30. https://doi.org/10.3390/ijms20010030

144. Keyaerts E, Vijgen L, Pannecouque C, Van Damme E, Peumans W et al (2007) Plant lectins are potent inhibitors of coronaviruses by interfering with two targets in the viral replication cycle. Antiviral Res 75:179-187. https://doi.org/10.1016/j.antiviral.2007. 03.003

145. Mitchell CA, Ramessar K, O'Keefe BR (2017) Antiviral lectins: selective inhibitors of viral entry. Antiviral Res 142:37-54. https://doi.org/10.1016/j.antiviral.2017.03.007

146. Mishra A, Behura A, Mawatwal S, Kumar A, Naik L, Mohanty SS et al (2019) Structure-function and application of plant lectins in disease biology and immunity. Food Chem Toxicol 134:110827. https://doi.org/10.1016/j.fct.2019.110827

147. Lusvarghi S, Bewley CA (2016) Griffithsin: an antiviral lectin with outstanding therapeutic potential. Viruses 8:296. https://doi. org/10.3390/v8100296

148. Singh SS, Devi SK, Ng TB (2014) Banana lectin: a brief review. Molecules 19:18817-18827. https://doi.org/10.3390/molecules1 91118817

149. Balzarini J, Hatse S, Vermeire K, Princen K, Aquaro S et al (2004) Mannose-specific plant lectins from the Amaryllidaceae family qualify as efficient microbicides for prevention of human immunodeficiency virus infection. Antimicrob Agents Chemother 48:3858-3870. https://doi.org/10.1128/AAC.48.10.38583870.2004

150. Ismaya WT, Tjandrawinata RR, Rachmawati H (2020) Lectins from the edible mushroom Agaricus bisporus and their therapeutic otentials. Molecules 25:2368. https://doi.org/10.3390/molec ules 25102368
151. Ritchie G, Harvey DJ, Feldmann F, Stroeher U, HeinzFeldmann DRA, Rudd PM (2010) Identification of N-linked carbohydrates from severe acute respiratory syndrome (SARS) spike glycoprotein. Virology 399:257-269. https://doi.org/10.1016/j.virol.2009. 12.020

152. Gupta A, Sandhu RS (1996) A new high molecular weight agglutinin from garlic (Allium sativum). Mol Cell Biochem 166:1-9. https://doi.org/10.1023/A:1006827921151

153. Gupta A, Sandhu RS (1996) Mitogenic activity of high molecular weight mannose specific agglutinin. Ind J Biochem Biophys 33:325-327

154. Gupta A, Sandhu RS (1997) In vivo binding of mannose specific lectin from garlic to intestinal epithelium. Nutr Res 17:703-711. https://doi.org/10.1016/S0271-5317(98)00069-4

155. Gupta A, Sandhu RS (1998) Effect of garlic agglutinin and garlic extracts on the rat jejunum. Nutr Res 18:841-850. https://doi.org/ 10.1016/S0271-5317(98)00069-4

156. Karasaki Y, Tsukamoto S, Mizusaki K, Sugiura T, Gotoh S (2001) A garlic lectin exerted an antitumor activity and induced apoptosis in human tumor cells. Food Res Int 34:7-13

157. Gupta A (2020) Emerging applications of lectins in cancer detection and biomedicine. Mater Today Proc. https://doi.org/ 10.1016/j.matpr.2020.05.810

158. Clement F, Pramod SN, Yeldur P, Venkatesh YP (2010) Identity of the immunomodulatory proteins from garlic (Allium sativum) with the major garlic lectins or agglutinins. Int Immunopharmacol 10:316-324. https://doi.org/10.1016/j.intimp.2009.12.002

159. Liu CT, Su HM, Lii CK, Sheen LY (2009) Effect of supplementation with garlic oil on activity of Th1 and Th2 lymphocytes from rats. Planta Med 75:205-210. https://doi.org/10.1055/s0028-1088396

160. Dam TK, Bachhawat K, Rani PG, Surolia A (1998) Garlic (Allium sativum) lectins bind to high mannose oligosaccharide chains. J Biol Chem 273:5528-5535. https://doi.org/10.1074/jbc. 273.10.5528

161. Barre A, Bourne Y, Els J, Van Damme M, Peumans WJ, Rougé $P$ (2001) Mannose-binding plant lectins: different structural scaffolds for a common sugar-recognition process. Biochimie 83:645-665

162. Bewley CA, Cai M, Ray S, Ghirlando R, Yamaguchi M, Muramoto K (2004) Cyanobacterial protein MVL: NMR, ITC and sedimentation equilibrium studies. I Mol Biol 339:901-914. https://doi.org/10.1016/j.jmb.2004.04.019

163. Liu Y-M, Shahed-Al-Mahmud M, Chen X, Chen T-H, Liao K-S, Lo JM et al (2020) Carbohydrate-binding protein from the edible lablab beans effectively blocks the infections of influenza viruses and SARS-CoV-2. Cell Rep. 2020:108016. https://doi.org/10. 1016/j.celrep.2020.108016

164. da Silva LCN, Correia MTS (2014) Plant lectins and Toll-like receptors: implications for therapy of microbial infections. Front Microbiol 5:20. https://doi.org/10.3389/fmicb.2014.00020

165. Coelho LCB, dos Santos Silva PM, de Meneze sLima VL, Pontual EV, Paiva PMG et al (2017) Lectins, interconnecting proteins with biotechnological/pharmacological and therapeutic applications. Evid Based Complement Alternat Med 1:11. https://doi.org/10.1155/2017/1594074

166. Lagarda-Diaz I, Guzman-Partida AM, Vazquez Moreno L (2017) Legume lectins: proteins with diverse applications. Int J Mol Sci 18:1242. https://doi.org/10.3390/ijms18061242

167. Jandú JJB, Neto RN, M, Zagmignan A, de Sousa EM, et al (2017) Targeting the immune system with plant lectins to combat microbial infections. Front Pharmacol 8:671. https://doi.org/10.3389/ fphar.2017.00671

168. Singh RS, Walia AK (2018) Lectins from red algae and their biomedical potential. J Appl Phycol 30:1833-1858. https://doi. org/10.1007/s10811-017-1338-5 
169. Akkouh O, Ng TB, Singh SS, Yin C, Dan X, Chan YS et al (2015) Lectins with anti-HIV activity: a review. Molecules 20:648-668. https://doi.org/10.3390/molecules20010648

170. Mazalovska M, Kouokam JC (2018) Lectins as promising therapeutics for the prevention and treatment of HIV and other potential coinfections. Biomed Res Int. https://doi.org/10.1155/2018/ 3750646

171. Günaydın G, Edfeld G, Garber DA, Asghar M, Noël-Romas L et al (2019) Impact of Q-Griffithsin anti-HIV microbicide gel in non-human primates: in situ analyses of epithelial and immune cell markers in rectal mucosa. Sci Rep 9:18120. https://doi.org/ 10.1038/s41598-019-54493-4

172. Saïdi H, Nasreddine N, Jenabian M-A, Lecerf M, Schols D, Krief C (2007) Differential in vitro inhibitory activity against HIV-1 of alpha-(1-3)- and alpha-(1-6)-D-mannose specific plant lectins : implication for microbicide development. J Transl Med 5:28. https://doi.org/10.1186/1479-5876-5-28

173. Covés-Datsona EM, Kingc SR, Legendrec M, Gupta A, Chand SM et al (2020) A molecularly engineered antiviral banana lectin inhibits fusion and is efficacious against influenza virus infection in vivo. Proc Natl Acad Sci (USA) 117:2122-2132. https://doi. org/10.1073/pnas.1915152117

174. Sato Y, Morimoto K, Hirayama M, Hori K (2011) High mannosespecific lectin (KAA-2) from the red alga Kappaphycus alvarezii potently inhibits influenza virus infection in a strain-independent manner. Biochem Biophys Res Commun 405:291-296. https:// doi.org/10.1016/j.bbrc.2011.01.031
175. Sato Y, Hirayama M, Morimoto K, Yamamoto N, Okuyama S, Hori K (2011) High mannose-binding lectin with preference for the cluster of $\alpha 1-2$-mannose from the green alga Boodlea coacta is a potent entry inhibitor of HIV-1 and influenza viruses. J Biol Chem 286:19446-19458. https://doi.org/10.1074/jbc.M110. 2166555

176. Regente M, Taveira GB, Pinedo M, Elizalde MM, Ticchi AJ, Diz MS et al (2014) A sunflower lectin with antifungal properties and putative medical mycology applications. Curr Microbiol 69:88-95. https://doi.org/10.1007/s00284-014-0558-z

177. Roma HL (2020) COVID-19 and cytokine storm syndrome. Medical Laboratory Observer, Siemens Healthineers, Mumbai

178. Teixeiraa CS, Assreuy AMS, Osterne VJS, Amorim RMF, Brizeno LAC, Debray H et al (2014) Mannose-specific legume lectin from the seeds of Dolichos lablab (FRIL) stimulates inflammatory and hypernociceptive processes in mice. Process Biochem 49:529-534. https://doi.org/10.1016/j.procbio.2013.12.020

179. Van Damme JM, Allen AK, Peumans WJ (1987) Leaves of the orchid twayblade (Listera ovata) contain a mannose-specific lectin. Plant Physiol 85:566-569. https://doi.org/10.1104/pp.85.2. 566

Publisher's Note Springer Nature remains neutral with regard to jurisdictional claims in published maps and institutional affiliations. 